\title{
PROLEGÓMENOS ONTOLÓGICOS Y GNOSEOLÓGICOS A UNA DISCUSIÓN SOBRE EL NATURALISMO FILOSÓFICO Y SUS LÍMITES
}

\author{
José Domingo Vilaplana. Universidad de Sevilla
}

"Las filosofías que inquietan la presunción del hombre
deben resignarse a la proscripción y a la calumnia."
Nicolás Gómez Dávila, Breviario de escolios

Resumen: Creo que lo que llamamos, o suele llamarse, conocimiento científico tiene mucho de juego de magia lingüístico, tiene mucho de sobrentendidos solapados. En este ensayo intento identificar, mostrar y hacer visibles algunos de los mecanismos que provocan el ensalmo lingüístico-psicológico por el que se otorga realidad objetiva a dicho conocimiento y, por extensión, a sus derivaciones doctrinales, el naturalismo entre ellas. A continuación, ahondando en las limitaciones de la comprensión científica de la realidad, abordaré el problema de las propias limitaciones del naturalismo, tanto en su versión doctrinal como programática, implicadas de la falsa presunción de objetividad y de verdad del discurso científico.

Palabras clave: entendimiento, comprensión, explicación, justificación, plano de la realidad, existencia.

Ontological and gnoseological prolegomena for a discussion about philosophical naturalism and its borders.

Abstract: I consider what we mean, or what is usually meant, by scientific knowledge is to a great extend a magic trick of language and conveys veiled implications. In the present paper I will try to identify, show and reveal some of the mechanisms which inspire or provoke the linguistic-psychological spell whereby the quality of objective reality is bestowed upon scientific knowledge and, by extension, upon its doctrinal derivatives, among them naturalism. Delving into the limits of the scientific comprehension of reality, I will then approach the limitations of naturalism itself, both as a philosophical doctrine and a programme wrapped in the false presumption of objectivity and the truth of scientific discourse.

Keywords: understanding, comprehension, explanation, justification, sphere of reality, existence.

Recibido: 20 de abril de 2020. Aceptado: 1 de junio de 2020. 
José Domingo Vilaplana

\section{Preámbulo}

El naturalismo es, probablemente, la primera doctrina filosófica. Nace la filosofía, en la antigua Hélade, bajo el dogma de que "todo lo verdaderamente existente es natural" (F. Cornford), siendo lo natural el modo de ser de lo material instruido por el logos. Explicar y comprender el orden natural ha sido, pues, la primera tarea que se impuso la búsqueda filosófica. Desde esta perspectiva, la ciencia positiva que actualmente asume su condición naturalista, y materialista, cabe decir es una extensión de la propia búsqueda filosófica; una extensión que, sin embargo, ha alcanzado una plena autonomía respecto a su matriz originaria. Autonomía que, mutatis mutandis, también el propio ser humano se ha otorgado, la buscaba desde el principio del filosofar, hasta perder — de facto- cualquier vínculo heterónomo. La autonomía de la ciencia, y su brillante expediente, parecen haber inducido en el hombre occidental su propia certeza de autonomía.

Que la ciencia de los hechos naturales haya alcanzado dicha autonomía no implica ni que responda todos los problemas que desde la filosofía se plantean o formulan relativos al mundo físico y a la posibilidad de conocerlo de forma objetiva y universal, ni tampoco que sus modelos explicativos estén exentos de limitaciones, inconsistencias y arbitrios ideológicos. Contra lo que suele creerse. Como tampoco ha logrado, a pesar de su brillante expediente, la plena naturalización del ser humano, también contra lo que suele creerse.

Pretendo a continuación realizar un análisis tanto de las pretensiones naturalistas como del alcance gnoseológico en que estas pretensiones se fundan. Y esto, desde la perspectiva crítica que adopto, no resulta nada fácil, como tampoco sus resultados son satisfactorios, ni para mí ni, mucho me temo, para nadie. Y no pueden serlo por el mismo motivo que suscita la realización, o la necesidad de realización, del propio análisis: la condición insatisfactoria de las certidumbres que aportan las palabras, bien aisladas o trabadas en discursos, unido a la imposibilidad de salir o escapar del ámbito 
que ellas configuran, es decir del ámbito del discurso. Hay crítica y hay análisis porque no hay certezas más allá de lo que hayamos decidido que lo sea, y como no todos tomamos la misma decisión en función de los mismos criterios ni respecto a los mismos candidatos a certezas, ponemos en marcha nuestro propio análisis crítico en busca de las nuestras. Así, son palabras las que pretenden servir para criticar y analizar construcciones hechas también de palabras, lo que le exige a las palabras del análisis y de la crítica el mismo nivel de eficacia que les asistió durante el proceso de construcción del edificio que ahora se pretende demoler o remodelar, también con palabras. ¿Son palabras distintas, las del análisis y las del objeto que se analiza?, ¿̇son otra sintaxis y otra lógica las que operan en ambos ejercicios, constructivo y deconstructivo o analítico? No lo creo, pero no lo sé. Más bien pienso que se produce un entrecruzamiento de distintos niveles, en altura y profundidad, que configuran distintos planos de discurso, a veces conectados por audaces estrategias de intercomunicación o intertraducción, estrategias interdisciplinares que pretenden abrir nuevos horizontes comprensivos, desde los que acaso se forjen nuevas certezas, nuevas formas ilusionadas de verdad.

Sabedor de que busco mis propias certezas transitorias, en este caso criticando o desmontando las ajenas, intentaré identificar algunas de las piezas constitutivas del discurso científico, esto es del relato que la ciencia construye acerca del objeto que investiga; piezas en las que creo reconocer las claves que otorgan la pretendida certeza que el discurso científico atesora. Desde ahí ensayaré, al menos esbozada, una crítica al naturalismo desde su raíz, el materialismo cientificista, evitando incurrir en las descalificaciones sumarias y en las ridiculizaciones sofísticas que con tanta frecuencia sus prosélitos practican, por más tentador que sea pagar con la misma moneda. Pero esto ni es una guerra ni tampoco un programa de entretenimiento. Por mi parte, esta crítica nace, y no tiene otro propósito, aunque quede insatisfecho, de mi propia necesidad de comprensión cabal y justificación veraz, 
José Domingo Vilaplana

algo que sigue caracterizando la búsqueda filosófica que algunos practicamos, acaso no tan ebrios de soberbia autonomía, por eso quizá tan proclives a reconocer nuestras limitaciones.

\section{Naturalismo y Ciencia}

No son objeto de este trabajo abordar, ni siquiera marginalmente, la historia de la ciencia y del naturalismo, pero sí poner de manifiesto, como ineludible punto de arranque, su indisoluble vínculo y señalar su mutua influencia. En la actualidad, y desde el siglo XX, el vínculo naturalismociencia es tan fuerte que cada uno reclama al otro como calificativo esencial: naturalismo científico, o ciencia naturalista. A su vez, la asociación de tal calificativo - naturalista - a la ciencia ha devenido en proyectar sobre la propia ciencia la misma carga doctrinal que el sufijo - ismo denota, figurando así una supuesta corriente, acaso más filosófica o ideológica que científica, a mi juicio inserta en el naturalismo: el cientismo o cientificismo, que otorga a la ciencia positiva y a sus métodos la facultad de obtener la forma más valiosa de conocimiento, tesis que de partida comparte el naturalismo. De ese modo, queda establecido el marco de realidad que el naturalismo científico o la ciencia naturalista, como el propio cientismo, adoptan como objeto y referencia únicas. Tal referencia es la realidad físicomaterial: la naturaleza material como única manifestación de realidad susceptible de ser conocida por la única forma de conocimiento digno de ser así considerado, en virtud de la verdad objetiva que expresa. El naturalismo científico y el cientismo acotan, pues, tanto la realidad cognoscible como el conocimiento de la realidad. El naturalismo, en tanto reconoce a la naturaleza como totalidad de realidades físicas existentes, exhibe una concepción de lo real eminentemente materialista, pues esas realidades físico-naturales son originariamente materia. De igual modo, la ciencia, en tanto relato o narración —construcción gnoseológica- acerca de la naturaleza es, desde su más honda raíz, materialista, y por idéntico motivo, naturalista. El sufijo -ista/-ismo (son el mismo, en su acepción adjetiva o sustantiva) que viene 
apareciendo en estas conceptualizaciones no sólo denota una tendencia de carácter doctrinal o ideológico, ya señalada, sino que connota un cierre o clausura del dominio al que alude, un acotamiento, una reducción. Así "materialista", "naturalista" o "cientificista" connotan la consideración de que lo material, lo natural y lo científico constituyen dominios exclusivos, es decir únicos, y en este contexto, solapables. Así, lo material alude al orden único de realidad, lo científico al orden único del conocimiento, y lo natural al punto de encuentro entre lo material y lo científico, lo fenoménico. Por eso en el naturalismo quedan subsumidos materialismo y cientificismo, y por eso el naturalismo, filosóficamente considerado, es la afirmación de que no hay ciencia, es decir no hay conocimiento real, sino de lo natural-material, y que sólo lo natural-material es realmente real.

En la actualidad, y en términos populares, es el concepto de cienciala Ciencia- el que engloba y en no escasa medida oculta su núcleo materialista, así como suaviza o edulcora su inspiración naturalista, tan reductiva y excluyente. Preguntarse, pues, por los motivos o las causas de la primacía de la ciencia y de su liderazgo en el mundo occidentalizado exige, entre otros estudios que superan los propósitos de este trabajo, analizar y esclarecer las condiciones desde las que el relato científico naturalista conquista el grado de certeza que le otorga esa primacía, ese liderazgo. Veamos.

\section{El problema}

A modo de preguntas, el problema al que este estudio se consagra puede formularse como sigue: 1 . ¿Qué es lo que otorga certeza al discurso científico?; 2. ¿En qué sentidos y hasta qué punto lo que ese discurso expresa es conocimiento? El intento de responder, es decir su progresiva respuesta, a estas preguntas irá poniendo de manifiesto no sólo la complejidad sino la limitación de la expectativa que la propia ciencia naturalista genera respecto de sí misma y de sus posibilidades. Unas limitaciones de carácter, no sólo epistemológico (como se ha entendido desde la filosofía de la ciencia), sino eminentemente gnoseológico, por tanto estructurales y estructurantes. 
Unas limitaciones que, no obstante, no se traducen en impedir, lastrar o condicionar la propia actividad científica, que sigue su marcha hacia una meta indefinida y apoyada en unas certezas inquebrantables, ajena al problematismo de su propia actividad y a la íntima cualidad del conocimiento que genera, que de momento nos guardamos de calificar.

Las nociones de descripción, explicación, entendimiento, comprensión y justificación, así como las nociones de verdad, objetividad y universalidad, entre otras de las tradiciones filosófica y científica, se presentan como los términos de un léxico que galvaniza lo que pasa por ser considerado conocimiento. La misma imprecisión de los términos y la indefinición de sus límites provoca una fusión de los mismos por superposición que asimilada a lo que llamo "operatividad funcional o pautada", de la que son muestra la utilidad y la eficacia tecno-práctica del conocimiento científico, que constituyen su más solícita demanda, genera una acrítica ilusión de certeza objetiva que es equiparada a la verdad y con ella al valor del bien. Lo que aporta la satisfacción deseada es verdadero y bueno: tal viene a ser la divisa que prestigia a la ciencia. Así, la ciencia, y con ella las dos corrientes que le sirven de cobertura teórico-ideológica, el materialismo y el naturalismo, adquieren el prestigio blindado del que gozan desde hace no menos de tres siglos, pero que en la actualidad alcanza el rango de hegemónico y la convierten, a la ciencia (y a sus más destacados pajes, que se han erigido en brújula y piloto: el materialismo y el naturalismo), en líder y motor del progreso humano, en instructor del destino de los hombres y en respuesta a todos los males y bienes que le aquejan.

(Escribo estas líneas en pleno confinamiento domiciliario por la pandemia de covid-19; toda la población mundial mira hacia la ciencia con la confianza absoluta de que pronto dará con la respuesta adecuada para su control, o en cualquier caso está persuadida de que sólo la ciencia puede ofrecer esa respuesta. Y esa respuesta, cuando se logre, será expresión —así lo entiende la misma ciencia y toda la población mundial- del conocimiento que se logre alcanzar de la fisiología del coronavirus. El grado de certeza, pues, que se atribuye a las conquistas científicas es inseparable de 
la eficacia con que sea satisfecha la demanda. Esas conquistas científicas son asumidas como conocimiento conquistado, que es adoptado como conocimiento real de la realidad, el único. ¿Alguien se atreve, a falta de otro recurso salvífico, a cuestionar este dogma?)

Abordar el problema gnoseológico del peculiar realismo que practica el naturalismo científico requiere un minucioso análisis, más que del proceso de gestación de lo que se asume como ciencia, tradicional dominio de la epistemología y la filosofía de la ciencia, del propio lenguaje que edifica el conocimiento científico y, en último término, el discurso naturalista. La certeza del conocimiento no puede residir en el grado de utilidad, que a su vez establece grados de previsibilidad, con la consiguiente capacidad de intervención a distintos niveles de los procesos, según las necesidades. La certeza del conocimiento no reside, pues, en su espectacularidad (el logro de una eficaz vacuna contra el coronavirus): en ella puede residir su utilidad, que a su modo otorga una ilusión de certeza apoyada en la eficacia y en el servicio que presta. Tampoco la certeza del conocimiento científico puede residir en la familiaridad o sensación de dominio y confianza que proporciona respecto al medio o el entorno natural y vital, por más que logre estimular la sensación de haber satisfecho la necesidad de orientación. La certeza del conocimiento ha de ser una nota del conocimiento mismo, la condición de su verdad. Pero la verdad del conocimiento no se cifra ni siquiera en la prueba; la verdad del conocimiento se cifra, en todo caso, en el lenguaje. No hay conocimiento científico-natural sin lenguaje. La prueba empírica o experimental está al servicio del conocimiento y forma parte de su proceso de construcción, mas no es el conocimiento mismo que se busca y se expresa, como tampoco lo probado equivale a lo verdadero. El sintagma "conocimiento probado" carece de valor si ese conocimiento no es, o no ha sido, "expresado", como tampoco el sintagma "conocimiento verdadero". Y aún más: también la prueba empírica se concibe y se ejecuta desde una matriz lingüística, sobre la que se edificará el hallazgo teórico. El problema manifiesta sus aristas más cortantes toda vez que la gnoseología que opera 
en la edificación naturalista del conocimiento científico es eminentemente realista, lo que implica arrastrar el lenguaje que lo expresa hacia una concepción realista del mismo. Y aquí de nuevo será oportuno distinguir entre el valor de uso del lenguaje, y con él de la ciencia que expresa, y su valor de verdad, que no pueden ser equiparables, ni tampoco solapables. La equiparación y el solapamiento que subrepticiamente se ha venido realizando entre utilidad y verdad forma parte del nudo de confusiones y desplazamientos de significados que, como ya he dicho, nada obstaculizan el llamado "progreso de las ciencias", únicamente amparado en su capacidad de generar y satisfacer demandas (particulares y sociales o públicas) a pesar de la parcialidad y la limitación de las respuestas que ofrecen (ocultas —parcialidad y limitación - en la espectacularidad y la eficacia técnica o tecnológica), pero sí ponen muy seriamente en cuestión el valor de verdad de lo que pretende ser considerado conocimiento cierto de la realidad. A este nivel, o visto el conocimiento científico desde esta perspectiva problemática, las diferencias entre la especulación filosófica y la especulación científica parecen reintegrarse, y acaso reencontrarse, en la original matriz que inspiró la búsqueda racional y autónoma cuyos resultados nunca fueron ni concluyentes ni definitivos, por más que fueran, y sigan siendo, influyentes y transformadores.

\section{El discurso de la Ciencia naturalista}

No hay ciencia sin lenguaje y sin lengua ${ }^{1}$. La ciencia, a su vez, se expresa en un orden sintáctico y en un orden semántico, ya sea a nivel formal (lógico-matemático) como a nivel natural (áreas cerebrales del lenguaje y

1 Utilizo los conceptos lenguaje (1) y lengua (2) con los siguientes significados respectivamente: (1) capacidad de expresión y comprensión verbal estructurada a nivel cerebral; (2) sistema de signos implementados en las estructuras del lenguaje mediante los que hacemos efectiva la expresión y la comprensión verbal, tanto oral como escrita. La lengua, pues, cifra el contenido de la comunicación, cuya forma intrínseca otorga el lenguaje. En estas definiciones enfatizo los aspectos de ambos conceptos que en este contexto me interesa considerar o tener en cuenta. 
lengua natural). Si esto es así, la ciencia se construye sobre una tradición lingüística en permanente reajuste y renovación. El peso simbólico-semántico de esa tradición está inevitablemente presente tanto en el pensador científico, que ha recepcionado e implementado el código (natural y formal) del que se sirve para relacionarse con la realidad y pensarla, como en el caudal de su propia producción, que desde su primitiva relación con lo real se concreta en la producción de hipótesis, como primeros y espontáneos, incluso inconscientes, ensayos de explicación comprensiva. La verdad que la ciencia pretende hallar ha de manifestarse, es decir expresarse, en la explicación comprensiva, y como explicación comprensiva. A su vez, en ciencia natural, toda explicación comprensiva nace de un acto de entendimiento, que es entendimiento hacia, y de percepción, que es percepción de; el punto de encuentro entre ambos, sobre el que se funda la comprensión, lo constituye el solapamiento hacia-de. El valor de verdad, pues, de la explicación comprensiva reclama (requiere) de una clarificación tanto del acto de entendimiento, que es la antesala de la comprensión, como de la comprensión misma, fundada en la percepción de realidad a la que se dirige el entendimiento. ¿Dónde reside, entre este laberinto de planos entrecruzados y fundidos, la garantía que certifique la certeza de la objetividad de la comprensión, inevitablemente expresada en los enunciados conectados del discurso científico? Tal garantía constituiría lo que O. Bolnow llama el "punto arquimédico" del conocimiento, que una y otra vez se escurre como pez entre los dedos. Eso que se escapa entre los dedos y que no logramos señalar en el proceso de construcción del conocimiento, sería nada menos que lo que garantiza su verdad. Se da la paradoja, pues, entre tantas como se destapan en el análisis del discurso científico, de que justamente lo que se supone que éste encierra: verdad, es lo que se esfuma ante la mirada atenta. Es cuanto menos sospechoso que para que emerja la certeza subjetiva de verdad el sujeto haya de no pensar en ella, como en un juego de magia. Si piensas, si buscas, si miras, desaparece en un oleaje de dudas. Creo que lo que llamamos, o suele llamarse, conocimiento científico tiene mucho 
José Domingo Vilaplana

de juego de magia, es decir: tiene mucho de sobrentendidos solapados. Diseccionar algunos de esos sobrentendidos del bloque compacto de las explicaciones comprensivas que conforman el discurso científico (es decir, la ciencia misma, y sus derivaciones doctrinales, el naturalismo entre ellas) es, expresado de este otro modo, el intento que inspira este análisis.

Llegados a este punto (no al arquimédico) nuestra reflexión pudiera continuar por dos caminos, seguir por dos rutas distintas pero conducentes probablemente al mismo destino: una sería realizar un análisis de las palabras o los términos que jalonan el discurso de la ciencia naturalista, y valorar su alcance, que será el alcance del propio conocimiento científico: nos moveríamos en el ámbito de la "gnoseología del lenguaje científico" (que no es la epistemología, sino algo previo y fundante de la misma); otro sería adentrarnos en la búsqueda a nivel intelectivo y a nivel empirico o sensualista del nombrado punto arquimédico: nos moveríamos en el ámbito más ancho de la "filosofía del conocimiento" (que no se circunscribe a la filosofía de la ciencia, sino que apunta a algo previo y acaso también fundante de la misma). En este trabajo, a pesar de la cercanía y posible convergencia de ambas rutas, optaremos por seguir la primera. El motivo es que no sólo las habituales controversias entre naturalistas, o entre naturalistas y humanistas, o incluso entre los propios humanistas a la hora de enfocar sus críticas al naturalismo, o a las distintas versiones del mismo, son debidas a los particulares usos lingüísticos —imposibles de normalizar-, sino también porque la misma consideración del discurso científico, tanto en lo que afirma producir (explicaciones comprensivas de la realidad objetiva) como en lo que aspira a consumar (amparado en una supuesta capacidad justificadora), está marcada por el efectismo psicológico que ciertas palabras prestigiadas o sobredimensionadas provocan, en una espiral creciente y retroalimentada, autosostenida. No sólo se manifiesta imposible la normalización semántico-lingüística, sino que esa carencia o imposibilidad juega a favor del mantenimiento y perpetuación de una superchería (de un trucaje, de un engaño por sustitución de mercancía), que ya es asumida, a fuer de ignorada, o deliberadamente ocultada, como verdad real, a la que el 
conjunto de la sociedad está plegada por ensamblar su insatisfecha necesidad de absoluto a la hipersatisfecha necesidad técnica. Insisto en que la propia investigación científica opera ajena a esta mecánica psicológica, pero no del todo, porque gracias al ensalmo que provoca ese sucedáneo de absoluto (basta con ser creído), recibe todo lo que el prestigio otorga, desde dinero hasta poder, y con el poder la extraordinaria capacidad de influencia que puede ejercer quien sea considerado, y a sí mismo así se considere, el legítimo poseedor de la llave del futuro y del cofre de la verdad.

El discurso naturalista ineludiblemente se configura como un tapiz de palabras; toda su consistencia se logra en la trabazón lengua-lenguaje. Ambos, lengua y lenguaje, se ahorman mutuamente, produciendo la herramienta mental que nos conecta, más allá del contacto sensible, al mundo físico ${ }^{2}$. Pero el "mundo físico" no es una evidencia sensible inscrita en el mundo comprendido, tampoco es una entidad primitiva del sistema familiar de creencias: no es una realidad con la que nos manejemos en nuestra cotidianidad armonizada y previsible, sino una construcción abstracta lingüístico-intelectual cuya aparición es forzada de algún modo por la duda, la sospecha o la ruptura de la previsible armonía del primitivo mundo familiar, de lo contrario nadie se habría visto forzado a producir esa nueva locución, "mundo físico", presumiendo introducir con ella una nueva referencia real. La expresión "mundo físico", como las expresiones "materia", "conocimiento" o "naturaleza", surgen en definitiva de la emergencia de una doble conciencia: la de problema y la de ignorancia, lo que demanda la construcción de puentes — puentes lingüísticos- que cubran los hiatos abiertos en la previsible armonía del mundo comprendido. Estos puentes lingüísticos se irán incorporando al paisaje de lo real sustentando el peso de la realidad que dicen soportar. Nuevas generaciones irán sucesivamente asimilando ese paisaje heredado, como también edificando nuevos puentes

2 Estas reflexiones se centran - ya se dijo- en el conocimiento del orden de realidad que desde el naturalismo científico más canónico se adopta como objeto o referencia: el mundo físico-natural. No aborda la consideración de otras realidades o entidades de carácter, por ejemplo, ético o literario, es decir no naturales o culturales. 
que extiendan y amplifiquen el contacto con lo real, es decir: la concepción de lo real. Reparemos en que ese contacto/concepción de lo real es instruido por y desde el sistema lengua-lenguaje, una supraentidad híbrida entre pública y privada, cuya función es, precisamente, esa: conectar, comunicar, poner en común, relacionar. Todas esas formas de contacto cifradas lingüísticamente generan desde la infancia, incluida la infancia del científico y del filósofo, un orden comprendido, un mundo comprendido, susceptible de ser descrito o expresado, esto es exhibido mediante la herramienta mental de la lengua ${ }^{3}$. Adquiere por tanto la lengua, a través de su léxico, una capacidad deíctica o señaladora: la palabra señala algo del mundo comprendido, y lo hace en la doble dirección, pública (hacia y para otros) y privada (hacia y para uno mismo). Pero lo simbólico enseguida, o muy pronto, adquiere una consistencia propia y progresivamente desligada del mundo del que originalmente fue rehén, invirtiéndose los roles de tal suerte que es el mundo físico originario, aquél susceptible de ser señalado por la palabra, el que finalmente queda confinado bajo la férula de lo simbólico, cada vez más polisémico, cada vez más polivalente y abstracto. El signo, pues, se ha erigido en símbolo, y así lo signado se ha hecho mental.

La pretensión naturalista (objetividad, universalidad, necesidad, verdad) requiere la supresión de lo simbólico y la regresión a —o regeneración de- una lengua de función estrictamente deíctica, bajo el supuesto de la eficacia que esa función comportara, es decir que lo real extraligüístico sea efectivamente señalado unívocamente por la lengua, y no sólo por las palabras. Tal sería la base y condición de una auténtica identificación, descripción, explicación y justificación científica de los hechos o los procesos reales. La elaboración de lenguajes formales ha estado inspirada por esa exigencia de univocidad y eficacia, es decir de precisión objetivadora. Sin embargo, no es tan fácil (nadie dijo que lo fuera) ni tan factible (esto sí

3 En lo sucesivo, al sistema lengua-lenguaje podré aludir mediante cualquiera de las dos palabras: lengua o lenguaje, según pretenda enfatizar un aspecto u otro del sistema que conforman. No debe olvidarse que se trata de una entidad privatizada, por tanto, apropiada y asimilada por cada sujeto desde su normalización pública o publicada mediante el uso. 
cuenta con mayor consenso) evadirse de la lengua natural ni del mundo por y desde ella simbolizado y comprendido, es decir, mentalizado.

Sólo la consideración preliminar del carácter histórico de la lengua, ya limita, si es que no anula de raíz, la pretensión científico-naturalista de conocimiento, que en cualquier caso refiere al conocimiento de lo real anterior y con independencia a la propia lengua ${ }^{4}$. Lengua que, por lo demás, es depositaria de tal caudal de usos simbólicos que literalmente convierte cualquier intento de precisión en un ejercicio de renovación —que no de novación-, como si de un permanente recauchutado lingüístico se tratara, lo que en la práctica se afronta realizando denodados viajes al pozo de las etimologías y enganchando raíces y otras partes de la anatomía de las palabras en ocurrentes neopalabras que digan lo que queremos decir y señalen lo que queremos señalar, identificar o describir. O explicar y justificar.

El conocimiento que dice expresar el discurso naturalista ha sido tejido, por tanto, por el procedimiento combinado de observación y traducción. A su vez, los procedimientos de observación han devenido progresivamente más complejos y sofisticados hasta hacerse eminentemente experimentales, pero en cualquier caso requieren disponer de la herramienta lingüística que deje constancia de sus resultados, que los exprese y los identifique, lo que igualmente redunda en una creciente sofisticación de los mecanismos de traducción. Inevitablemente esos procesos, progresivamente sofisticados, de observación/traducción son de carácter constructivo: se construye el conocimiento, como se construye un experimento. Del mismo modo que la observación primitiva (la que practicaron los primeros físicos o practicamos cualquier observador actual como inicial vía de búsqueda comprensiva directa, no experimental) exige la imposible supresión de la precomprensión en la que el observador se ve inmerso, el conocimiento que el científico

4 Detalle éste no menor, por cuanto el descubrimiento realista de lo que sea considerado conocimiento objetivo, incluso en sus fases históricas de gestación, como consecuencia de la investigación científica, requiere habilitar la lengua y con ella el léxico y la sintaxis que le son propias a la realidad, que ahora será realidad conocida por adecuadamente expresada. Será inevitable volver sobre este asunto más adelante. 
José Domingo Vilaplana

naturalista cree abstraer teóricamente de la experimentación presume la superación o desvinculación por su parte de todos los condicionantes psicolingüísticos con los que éste piensa e imagina. Sin embargo, y no hay ningún motivo que lo refute, el investigador carga irremediablemente con una precomprensión del mundo que considera real, y ello condiciona su búsqueda, como condiciona su hallazgo, porque es su forma misma de pensarlo y de reconocerlo lo que está condicionado: no busca donde no considera que hay algo que hallar, ni encuentra contra su más íntima y acaso inconsciente concepción de lo que haya de ser hallado. ¿Dónde reside, pues, la objetividad de ese conocimiento que se construye o se edifica? Mi respuesta será que ese conocimiento adquiere la objetividad de una creencia nacida de la fusión de lo que busco con lo que hallo, y de la proyección de lo que busco en lo que hallo.

Cabe pues apreciar dos niveles integrados e integrantes en y de lo que el científico naturalista llama conocimiento: el nivel experimental y el nivel al que lo experimentado aflora, que se concreta y se explicita en el nivel del discurso. Y dos son los problemas que de forma genérica se abordan en este trabajo: el problema de la objetividad del conocimiento (que involucra de manera decisiva el problema de su expresión en el discurso científico) y el problema de las limitaciones del naturalismo, implicadas desde la limitación que impone la falsa presunción de objetividad y de verdad del discurso científico. Conviene en este punto aproximar lo encontrado con lo buscado para de ese modo mantener la búsqueda correctamente orientada en pos del hallazgo final.

¿En qué formas se manifiesta la expresión de la pretendida objetividad de lo que el discurso naturalista contiene? O formulado más sintéticamente: ¿Qué formas de expresión adopta el discurso científico? Reparemos en que no trato tanto de establecer el fundamento de la objetividad, ese punto arquimédico del que habla Bolnow, sino de identificar las formas expresivas en que esa objetividad se manifiesta. Doy por descontado el carácter infundado de la objetividad naturalista, pero creo que sin necesidad 
de adentrarse demasiado en la filosofía del conocimiento en general es posible desde el examen de las formas de expresión de los contenidos del conocimiento naturalista determinar el grado de consistencia objetiva y, consecuentemente, sus límites. Doy también por descontados sus indiscutibles valores, de la ciencia natural, que por tanto no discuto y reconozco, aunque también sobre ellos considero necesario un ejercicio de clarificación. El establecimiento de sus límites ayudará a esa clarificación.

\section{Las formas de expresión del discurso naturalista}

Llamo "formas de expresión del discurso naturalista" a los modos o maneras que adopta el conocimiento científico-natural en el relato verbal y los sobrentendidos que esos modos involucran. Entiendo que sin relato verbal, es decir, sin discurso narrativo, no hay conocimiento; el conocimiento es y está en el relato. Fuera del relato está lo no comprendido, una existencia que no ha sido hallada, una ausencia de concreciones, o eso que con total impropiedad, o viciada desaprensión realista, suele llamarse los hechos y los procesos reales propios de las entidades materiales, mas no el conocimiento de los mismos, que sólo lo es en el relato y como relato ${ }^{5}$. Lo que pretendo realizar a continuación es un análisis de esas formas del discurso, esas formas que adopta el relato, a fin de establecer cuánto conocimiento albergan, es decir hasta qué punto cabe asumir lo que expresan como conocimiento. Se trata, en definitiva, de clarificar la laberíntica relación entre el hallazgo científico y su expresión lingüística.

5 Una obra de referencia para profundizar en el análisis de la relación entre realidad y formalización lingüística es el ensayo de John Henry Woodger Biología y lenguaje, Madrid, Tecnos, 1978. A mi juicio, y contra las tesis de Woodger, la formalización de los enunciados en ningún caso le otorga otra objetividad al contenido respecto de la que ya tuviera, aunque lo puede disponer para hacer con él todo el malabarismo deductivo que la lógica permita y proyectar consecuencias que pueden profundizar en la comprensión, pero su contenido objetivo, así como su objetividad, seguirá dependiendo del/la que ya albergaran los enunciados primitivos. La formalización no aporta más contenido ontológico ni más objetividad gnoseológica, tan sólo normalidad intersubjetiva. 
José Domingo Vilaplana

Así como la investigación científica se realiza en laboratorios de experimentación o en escenarios que hagan posible la observación (imaginemos a un equipo de bioquímicos en su laboratorio estudiando el ciclo de las pentosas fosfato o a un zoólogo en el campo extremeño observando estudiando- la vida de los martinetes), la producción científica, esto es, los resultados concluyentes de esa investigación, serán presentados a la comunidad científica a modo de publicaciones por los canales habilitados para tal fin. Los artículos y monografías son los géneros publicitarios en que la investigación científica muestra sus producciones (lo que de un modo ramplón suele llamarse "literatura científica"), textos que son estudiados, discutidos, contestados, asumidos o rechazados por otros miembros de la comunidad, y que serán también traducidos, recensionados, citados, interpretados por quienes, por los motivos que fueren, los adoptan como instrumentos para la realización de su propia actividad. Los consensos, parciales o totales (raramente), en torno a los resultados que dichas publicaciones exhiben van generando y consolidando un "cuerpo" doctrinal así como una historia del asunto, problema u objeto de estudio; esa historia comprende desde los procesos de investigación hasta los distintos hitos en forma de hallazgos capitales sucedidos hasta el momento presente, el momento histórico actual en que se encuentre el estado de la cuestión. Un texto, entre tantos que pudieran seleccionarse como modelos de publicación científica, es el que firman Thomas D. Albright, Thomas M. Jessell, Eric R. Kandel y Michael I. Posner, publicado originalmente en Cell, 2000, con el título "Neural Science. A century of progress and the mysteries that remain", traducido al español con el título "Neurociencia. Un siglo de progreso y misterios que aún perduran”, y publicado como capítulo 5 del libro Psiquiatría, psicoanálisis y la nueva biología de la mente, del premio Nobel 
de Medicina o Fisiología en el año 2000 Eric R. Kandel, Barcelona, Ars Medica, 2006, pp. 211-3436. Damos por sentado que se trata de un texto científico, puesto que tanto la exposición histórica ${ }^{7}$ como la relativa al estado de la cuestión al menos hasta el año 2000, informan mediante una explicación secuenciada de los hallazgos consolidados y de los procedimientos por que tales hallazgos fueron conquistados (experimentos cruciales), e incluso de cómo unos hallazgos engendraron otros al estimular la imaginación y creatividad de los científicos para reorientar las líneas de investigación por selección de las hipótesis más plausibles, o que así parecieran. El resultado de ese largo proceso, a fecha del año 2000, es haber decantado un depósito de saber, saber normalizado en términos teóricos, pero nacido de la investigación científica, una actividad en la que entra en juego a partes que no es ahora el momento de dilucidar un universo de precomprensiones y certezas incuestionadas, es decir asumidas por los investigadores a lo largo de su formación científica y en el curso de sus vidas, junto al constante ejercicio de sus facultades imaginativas y creativas, que

6 Considero este texto de Kandel y colaboradores una pieza canónica del ensayo científico. Por otro lado, en lo que compete a las tesis que defiendo, en él se aprecia con nitidez la relación y dependencia entre búsqueda, hallazgo y lengua.

7 No pretendo afirmar, sin embargo, que una explicación de carácter histórico, en general, sea equivalente a la explicación científica, o que ostente el mismo rango de cientificidad. Como tampoco que la descripción ni la justificación históricas, en general, lo sean respecto de sus homólogas científicas, aunque en ambas áreas tanto la descripción como la justificación recurran al uso de modelizaciones matemáticas (a distinto nivel de complejidad) y al principio de causalidad como principio justificativo. Lo que sí afirmo es que las introducciones históricas con las que muchos autores inician sus artículos y monografías científicas Kandel, entre otros - compendian el proceso de investigación relativo al objeto de su investigación, respecto de cuyo estado a continuación él aportará novedades que deberán ser integradas en el devenir histórico de la investigación; y también afirmo que las narraciones sucesivas del proceso investigador y de sus hallazgos conforman un cuerpo doctrinal específico que se engarza o se une a otro cuerpo mayor del que a su vez se ha nutrido - y del que en cierto modo también ha derivado- para poder progresar. Se ofrece desde esta consideración una imagen de la ciencia como si de un gran cuerpo ensamblado y en constante proceso de ensamblaje se tratara. Las crisis y las revoluciones científicas limpian o aligeran ese cuerpo de lo que se revela inservible y mantienen lo que aún es útil, es decir explicativamente valioso. 
van desde la búsqueda del modelo experimental idóneo hasta la concepción de los más extravagantes y a veces genialmente disparatados experimentos, en que la audacia y un indeclinable afán por atrapar lo que buscan (produciéndose a veces inesperados y felices encuentros o decepcionantes fiascos) se alían a la confianza primordial que sustenta todo el procedimiento de búsqueda y la búsqueda misma: la confianza en las posibilidades de hallazgo, y la confianza en que lo hallado será, si no más, al menos una esquirla de realidad objetiva, de tal modo que al expresarla, esto es al traducirla al lenguaje, dicha esquirla de realidad, tanto si se trata de una entidad o un proceso (son indiferentes en este contexto), queda señalada, queda identificada e incorporada funcionalmente al depósito de saber conquistado, al depósito de la ciencia.

Pero detengamos nuestra atención en el hallazgo mismo, en la circunstancia condicionante de su contextualización funcional, que es lo que lo consagra como tal hallazgo. Entiendo, en virtud de esa contextualización funcional, que el hallazgo es simultáneo a su traducción lingüística, puesto que sólo expresado lingüísticamente, esto es, identificado, forma parte de un contexto funcional, que es un orden en el plano de la realidad comprendida. Quiero decir con esto lo siguiente, primero: que no hay hallazgo en sentido estricto si no hay posibilidad de traducción lingüística, la no traducibilidad supondría la imposibilidad de integrar lo hallado en un contexto comprendido, por tanto el propio hallazgo no sería comprendido, esto es, no sería tal hallazgo, sino algo perteneciente al ámbito del misterio, que puede involucrar tanto lo no comprendido como lo no comprensible ${ }^{8}$; segundo: que

8 Son planos distintos, el de lo no comprendido y el de lo no comprensible; si se habla de "misterio", por tanto, hay que explicitar el plano de comprensión sobre el que aplicamos el término en su forma sustantiva o adjetiva. El no hacerlo induce a la confusión de considerar misterio tanto lo no comprendido, pero comprensible, esto es, inteligible, cuando se den las condiciones adecuadas, como lo no comprensible, es decir lo que no es susceptible de ser comprendido o inteligido por su propia condición. Esta utilización laxa del término "misterio", sin determinar el plano de su aplicación, es habitual, dejando en la sombra la cuestión de si quien, como Kandel, por ejemplo, califica de misterio algo desconocido lo hace sólo 
sólo se halla lo que se puede comprender, es decir lo que puede ser integrado funcionalmente en algún contexto u orden en el plano de la realidad que se va construyendo en los relatos científicos. La traducibilidad no es una mera susceptibilidad de ser nombrado, sino de ser inscrito comprensivamente en un contexto comprendido; traducibilidad es la forma que adopta la inteligibilidad; lo traducido es, pues, lo comprendido. Pretendo que se aprecie, desde estas consideraciones, la íntima cercanía o proximidad entre el qué es lo hallado respecto al cómo funciona lo hallado: se ha hecho tan estrecha esa cercanía que el no reparar en la distancia que los distingue y los separa ha provocado entre ambos una soldadura metonímica de consecuencias perversas, porque la fusión del plano del ser con el de la función desliza la justificación del ser hacia su función, que es siempre una derivación tecno-cultural. Este dislate reductor es lo que refuerza, por hábito tan desaprensivo como interesado, la pretensión de objetividad y de verdad del conocimiento científico y de todos sus derivados doctrinales, así como su prestigio, puesto que sólo se construye, léase: se conoce, lo que funciona. De un vicio, o de algo más: de una impotencia, ha decantado la ciencia una virtud susceptible de ser enunciada incluso en términos de principio garantista: No hay hallazgo que como tal pueda ser considerado hasta no quedar plenamente definido —expresado y comprendido - como realidad en términos de funcionalidad de sus elementos integrantes. Por ejemplo, Hans Adolf Krebs culmina en 1937 la identificación del ciclo metabólico del ácido cítrico; la búsqueda de esa ruta metabólica había comenzado muchos años

porque de momento lo desconoce pero es susceptible de llegar a conocerse, dado que nada de lo que sucede en el mundo es ininteligible para el ser humano, o, por el contrario, admite la posibilidad de que haya misterios imposibles de dilucidar para el intelecto humano, es decir, admite la posibilidad del plano de lo no comprensible. Pero el problema realmente candente, al margen de confusiones por imprecisión o laxitud en el uso y aplicación de términos, es determinar si ambos planos existen en tanto planos diferenciados, fronterizos. Más adelante abordaré esta cuestión esencial, pero ya adelanto que a mi modo de ver sí existen, y reservo para ocupar ese plano de lo no comprensible a la nuda existencia. Intentaré mostrar esta tesis en páginas sucesivas, así como algunas consecuencias fundamentales que de ello se derivan, relativas precisamente al plano de lo comprensible y a las expectativas de la comprensión científica. 
José Domingo Vilaplana

antes, pero hasta que Krebs, a quien le fue otorgado el Nobel de Medicina o Fisiología en 1953, no la configura identificando y describiendo todas las reacciones implicadas no se puede decir que se hubiera conquistado esa esquirla de realidad tan decisiva en la comprensión de la respiración celular (a partir la formación de la Acetil Co-A, desde el ácido pirúvico, a su ver procedente de la glucolisis, y el ingreso de los electrones y protones liberados en el ciclo a la cadena transportadora o cadena respiratoria). Tal es el tipo o cualidad de hallazgo que busca e incorpora el conocimiento científico, a esto se ha reducido de facto la aspiración científica: a la comprensión funcional, es decir, a lo comprensible.

Es precisamente sobre los componentes observacionales-experimentales, explicativos y justificativos presentes en los relatos científicos -ahí donde se expresa el conocimiento científico- sobre los que pretendo centrar ahora la atención, dado que al ser lo comprendido lo que funciona, lo que funciona no es ajeno a lo comprendido, sino que es el modo en que lo ha sido. Pero no hay comprensión fuera del discurso, por tanto, es en el discurso donde se dan las claves en que la comprensión misma se configura, configurando por tanto el modo que adopta lo comprendido.

Todo texto científico, si lo es, lo es porque lo que en él se expresa es ciencia. No lo es porque en él se aprecien indicios propios de los textos científicos: un texto científico no lo es porque formalmente lo sea, sino porque lo que en él se dice es considerado conocimiento científico, algo pues que no puede salir, ni prescindir, del texto. ¿Dónde reside, no obstante, la cientificidad de lo considerado conocimiento científico? Acabamos de discutir, en nota 7 , sobre la relativa cientificidad del relato histórico del proceso de hallazgo científico, y hemos concluido que siendo una faceta importante de la comprensión científica no es en sentido estricto ciencia, y no lo es porque el método de exposición histórico no es el mismo que el de la búsqueda y el hallazgo científicos, que involucra para lograr su expresión una peculiar adaptación del sistema lengua-lenguaje. El problema parece radicar, primero, y de nuevo, en la búsqueda y el hallazgo; luego abordaremos la expresión, de la que ni la búsqueda ni el hallazgo se pueden zafar. 
La búsqueda requiere una formación previa por parte del buscador, y ello constituye inexcusablemente una precomprensión de cierto orden de realidad. Es decir, el buscador científico (nos atenemos a este tipo) está habilitado con una lengua común y un código específico (que puede ser formal o tendente a la formalización, aparte del depósito de siglas y léxico específico que requiere) desde las que ha implementado y habilitado su precomprensión global y específica de la realidad. De manera espontánea, diríamos: natural o naturalizada, el buscador científico se mueve en una realidad señalada e identificada por su lengua, su lenguaje y sus códigos, entre sí tan íntimamente engarzados (lengua-lenguaje-códigos) que su mundo comprendido está solapado a su mundo aprendido a través de los códigos específicos de su ciencia, que opera así a modo de ventana abierta — también — a la realidad no comprendida. Desaprensivamente, los códigos científicos son adoptados como referenciados a una realidad encapsulada en ellos, del mismo modo que la lengua natural expresa una realidad supuestamente en ella referenciada. Creo que el realismo propio del naturalismo científico es una extensión del realismo implícito en el uso que hacemos del sistema lenguaje-lengua natural en la cotidianidad histórico-cultural de nuestro mundo comprendido. Todos los componentes observacionales y experimentales, es decir los hechos observados de manera directa o indirecta (experimental), han de ser identificados (y serán manejados desde esa identificación) con signos lingüísticos, de modo que esos signos serán considerados extensionalmente idénticos a lo real que encapsulan o signan. Una vez más, metonímicamente el signo sustituye, por presumirlo equivalente, a la realidad significada. Movernos y pensar en un universo de signos equivale — desaprensivamente, por pura presunción — a pensar y movernos en un universo real, comprendiendo por real lo signado, y comprendido lo real como es signado.

Ese otorgamiento de realidad a lo signado opera tanto a nivel de entidades concretas (a modo señalador, deíctico) como a nivel descriptivo, explicativo y justificativo de los aspectos cualitativos y cuantitativos tanto de dichas entidades como de los procesos y dinámicas reales. Y eso es lo que 
nos encontramos en el texto científico: de un modo superpuesto, sin delimitar, y fusionado en una totalidad acotada por su inicio y su final, un relato integrado por descripciones observacionales o experimentales, explicaciones comprensivas y justificaciones racionales (lógicas o demostrativas). Todos los niveles del sistema lengua-lenguaje y sus extensiones formalizadas (subsistemas) confluyen en otorgar una unidad de sentido (comprensiva) a un relato que desde sus significantes léxicos hasta el edificio que la totalidad del texto configura significan el modo de ser y comportarse de un segmento de la realidad. Pero lo significan comprensivamente, de lo contrario no lo significarían. Por tanto, y vista la cuestión de manera inversa, sin comprensión los signos nada significan. Esto obliga a que desde las descripciones hasta las explicaciones y justificaciones han de ser comprensivas, es decir han de ser o poder ser comprendidas, fusionándose así la comprehensión óntica a la comprensión mental. Pero esa fusión es antes, mucho antes, una asociación psicológica reforzada por la costumbre que una correspondencia real y objetiva entre significante y realidad. Esta sospecha, ineludible por cuanto el sujeto, sobre estar condicionado, condiciona sus representaciones de lo que adopta como objeto, obliga a analizar los textos científicos a fin de desgranar, no tanto o tan sólo la base o condición de su cientificidad, sino su universo comprendido, o dicho de un modo directo y sin rodeos: sus fronteras y, consiguientemente, sus limitaciones. Las fronteras y las limitaciones apreciables en los distintos niveles que forjan la arquitectura de un texto científico (quiero decir: de un texto cualquiera adoptado canónicamente como científico, relativo a cualquiera de las ciencias de la naturaleza física) son, pues, las fronteras y limitaciones del propio conocimiento científico, y por extensión del naturalismo cientificista, que asume la total arquitectura de la ciencia.

\subsection{Entender y comprender}

A mi juicio son dos, al menos, las fuentes que fundidas en un solo caudal generan una corriente que en su precipitado discurrir oculta la finitud de 
sus márgenes, por más que la corriente parezca no tener fin. El río resultante de esa doble afluencia es ancho, tanto que parece un mar; y su caudal se desplaza a distinto ritmo y velocidad históricas, pero imparable, hacia una meta inconcebible; prohibido volver la vista atrás, imposible cualquier intento de regresión, ni siquiera mirar a los lados: siempre al frente y sin desfallecer; el viento, además, sopla a favor. Por una fuente discurren los signos y las palabras (son lo mismo; los distingo sólo a efectos retóricos), todos los signos y todas las palabras, de todos los tipos y modalidades; por otra las presunciones, es decir las vanidades y sus ilusiones, revestidas de mil camuflajes. Es posible que sólo tengamos palabras y presunciones, pero fundidas constituyen una sociedad de inmenso poder, inagotable, algunos dicen que absoluto. ¿De qué estoy hablando, en este acaso confuso juego metafórico? Hablo de la irreprimible, o en tal parece haber devenido tras un cultivo de siglos, soberbia presunción humana. Eludir esta nota antropológica que reviste la conducta humana es tanto como observar a alguien que fuerza la cerradura de una tienda en plena avenida principal sin saber o siquiera sospechar que se trate de un ladrón, ignorando por tanto que la acción que observa, identifica y comprende está marcada, o puede estarlo, por esa condición del agente, lo que la convierte en otra respecto de la que parece. Mirar la ciencia naturalista sólo en la dirección que marca su caudal, dejarse llevar por su majestuosa corriente y servirse de sus frutos con la avara delectación de un pachá, o practicarla y heroicamente contribuir a incrementarla y a ampliar su alcance y dominio, pero ajenos a su alcance relativo y, aún más decisivo: ajenos a su natural limitación, supone además de un ejercicio de nefanda soberbia, una deliberada negligencia intelectual. Eludir reconocer las intenciones de quien fuerza la cerradura en plena avenida, convierte al transeúnte, acaso sin advertirlo, en cómplice del ladrón o, eventualmente, en su víctima, si comparte su avaro interés, como le sucede a las víctimas del timo de la estampita o del toco mocho. Pienso que la reflexión filosófica acerca de las limitaciones gnoseológicas del cientificismo naturalista es un esfuerzo por desanudar lo que se dice de lo que más allá de lo dicho se presume decir o hacer; sé que tiene algo de estéril este intento, y 
que nace condenado al silencio y casi a la mofa de que son objeto los excéntricos y los desgarrados en un mundo de obedientes triunfadores, pero en cierto modo se nos impone como un deber moral: si sospecho que quien fuerza la cerradura puede ser un ladrón, debo llamar la atención, a él y a la autoridad, y no seguir adelante, cómplice o cobarde, en pos de las mercancías que necesito, no importa si robadas o adulteradas.

Quizá las palabras que con más eficacia ocultan o camuflan la presunción (y pretensión ${ }^{9}$ ) de absoluto sean entendery comprender, términos presentes en todos los registros de uso, tanto popular como especializado. Todo relato científico pretende ser inteligible; pero, a su vez, la propia inteligibilidad que lo hace inteligible pretende corresponder — porque de ella se ha extraído en el proceso comprensivo de investigación, incluidos los procedimientos probatorios - a la misma inteligibilidad de lo inteligido, a su naturaleza propia, objetiva, ajena al sujeto; de ahí la supuesta verdad cifrada en el conjunto de signos que hace inteligible el texto científico. La inteligibilidad del texto es, pues, tomada por manifestación cierta de la inteligibilidad de la sección de realidad a la que el texto alude. El autor o los autores del texto, o de los textos científicos, en cada momento histórico, por tanto de hoy y de ayer, próximo y lejano, han cifrado mediante signos inteligibles la intelección lograda acerca de sus respectivas secciones de

9 La pretensión mantiene viva la presunción, la alimenta. Lo que originalmente (pongamos ese origen donde nos plazca en la historia de la humanidad al menos desde el neolítico) podría tomarse por un descuidado exceso, como un ímpetu de juventud, que habría de ser corregido en la madurez, se ha cronificado en forma de irreprimible y deliberada adicción: la pretensión de absoluto. Tal es así, que en la actualidad convive simbióticamente con los escepticismos y relativismos más enconados, sus aparentes contrarios. Por eso mi crítica a la presunción cientificista naturalista no es un canto a la sofística, tan pagada de soberbia relativista, sino un intento de denuncia, me temo que estéril, de los peligros a los que conduce a la humanidad la deliberada presunción/pretensión de la Ciencia y su acrítica sacralización, convertida en auténtico líder mundial, aliada con todas las formas del Poder y todos los colores del Dinero, que son la nueva trinidad de los dioses adorados. (Esa alianza es la que nos tiene, aún mientras escribo, confinados en casa, es decir, sometidos y esclavizados. Y no lo digo ni en broma ni metafóricamente, sino muy en serio y literalmente; cada tiempo tiene sus formas de esclavitud.) 
realidad, e incluso las ensamblan, en ejercicios también de fina cirugía léxico-científica, en secciones cada vez más amplias, cada vez más comprehensivas. La certeza sobre la verdad que expresa el texto científico estará en función de las garantías que ofrezca todo ese cúmulo de estrategias conducentes a otorgar y asegurar esa certeza: observación, experimentación, cuantificación, relación, inducción, deducción... nacidas y producidas en la corriente del sistema lengua-lenguaje y de sus subsistemas auxiliares. Al margen de esa corriente en la que adquieren su forma y su realidad, su comprensibilidad, los productos derivados de esas estrategias investigadoras no son nada, no existen; sin embargo, en ella, en la corriente del sistema lengua-lenguaje y sus subsistemas auxiliares, lo son todo, tanto que adquieren el estatuto de aquello que vicariamente suplantan en formas y términos lingüísticos: lo que de manera aún equívoca, pero baste por el momento, llamamos "la realidad misma" 10 .

Pero la dificultad reside en apreciar cómo el mismo procedimiento investigador, el mismo método, genera los presupuestos para blindar su certidumbre, y para reconocerla cuando se conquista. De este modo, entender y comprender, aun siendo dos momentos distintos pero conectados de la intelección del texto científico, parecieran erigirse también en momentos de la intelección de la "realidad misma", como si ésta fuera otra distinta a la comprendida en el texto. Así, en efecto, comprender el texto científico requiere de la misma facultad que comprender la "realidad misma", pero porque ésta no puede ser otra que la realmente inteligida, es decir la, o sea lo, expresada/expresado comprensivamente en el discurso científico. Obsérvense los dos planos en que pareciera desplegarse la realidad: la realidad textual, que es la expresada y por tanto la comprendida, y "la realidad

10 Eludo calificarla de "objetiva" porque a mi modo de ver la "realidad misma" pretende ser previa e independiente de la objetivación que operan el entendimiento y la comprensión. Pero esa "realidad misma", en rigor, no sale del texto, no es nada sin el texto, porque es una proyección operada por la propia comprensión, que es siempre comprensión de. Ese de contiene, y retiene, preposicionalmente lo comprendido en el texto, pues no es nada aparte de su expresión. 
misma", digamos, extratextual, o que presume serlo; ambos planos, no obstante, se constituyen en unidad bifronte en el momento de la comprensión, por eso toda comprensión, cuando se experimenta subjetivamente como tal, presume ser absoluta, plena, completa, porque es una realidad, objetiva en tanto objetivada, lo que se presume haber comprendido. Las dos caras de Jano son una sola... porque una no existe para la otra y viceversa. Y es que no puede, en rigor, haber otra sino la realidad comprendida, y en tanto que comprendida. Así, la subjetividad, o limitación, de toda comprensión se desvanece ante la presunción de objetividad comprendida. La "realidad misma" es la misma realidad comprendida, no hay otra.

Antes que el comprender fue el entender, tan inmerso en el mundo de las creencias familiares que literalmente nace de él a modo de extraviada derivación o disrupción respecto a la armonía de ese mundo comprendido del que emerge, de ese mundo familiar. Entender es, antes que nada, salirse o marginarse respecto a un orden previamente establecido, y "tender", "extenderse" hacia algo diverso, aún ignoto, pero capaz de mover, o traer, hacia sí la atención del sujeto. El sujeto entiende, es decir se siente atraído o dispersa su atención, pero aún no comprende lo que provoca esa distracción, en cierto sentido aún se encuentra extraviado, disperso. Sin embargo, ya se ha activado una búsqueda comprensiva, pero no para iniciar un regreso a la comprensión originaria, sino para abrirla, para ampliarla; se diría, pues, que el entendimiento hace de puente entre una comprensión del mundo y otra resultante de esa búsqueda que el entendimiento (en parte extraviado, en parte anclado a una comprensión previa del mundo) activa. El texto científico es el acta de lo que ha deparado esa búsqueda por los arrabales o los intestinos de un mundo, hasta entonces comprendido o familiar, que súbitamente se había hecho extraño o problemático. Por alguna circunstancia ${ }^{11}$ lo familiar conocido muta en algo extraño y ajeno, acaso nuevo, por tanto desconocido para el sujeto, que atrae su atención; atraído por lo extraño, lo

11 No es el momento de explorar esta cuestión, que nos retrotrae, cuando menos, al origen de la filosofía, y aún antes, al nacimiento de la conciencia. 
distinto, el sujeto en cierto modo, o hasta cierto punto, se des-entiende de su mundo familiar: es en ese momento de extravío consciente cuando el sujeto se erige en investigador de una realidad nueva, pero en tanto nueva, puesta - es decir: objetivada - en el mismo acto de fijar su atención y comenzar a entender, es decir comenzar a extenderse hacia ella desde su mundo comprendido, del que se va des-entendiendo. Comienza el sujeto a habilitar los medios necesarios para hacer comprensible la realidad nueva e integrarla comprendida en su mundo, que en cierto modo ya será otro. Los medios, pues, se habilitan al servicio de esa necesaria integración, por tanto la integración condiciona y define los medios, que ineludiblemente deberán cifrarse, para asegurar la traducibilidad que garantice la comprensión, en un alfabeto inteligible, comprensible. El texto científico es, pues, primero, el producto de una intelección, pero esa intelección no puede haberse logrado sin la imposición sobre el objeto del código que edifica el propio texto y certifica su inteligibilidad. Véase, hay algo redundante y recursivo entre el texto y la realidad de que en él se da cuenta, y es la redundancia de conocer aquello con lo que puedo conocer. Ahí topamos la otra margen de la limitación de la comprensión. Una fue la presunción de objetividad que se deriva de la unificación extensional texto/realidad en virtud de su común inteligibilidad. La otra es la limitación que impone el código que hace posible la inteligibilidad misma. Ambas limitaciones remiten entre sí, y entre ambas se acota el ámbito de la comprensión porque previamente se ha acotado, desde el momento mismo de su señalamiento, el ámbito de lo comprehendido. La certeza de la comprensión científico-natural de la realidad es siempre relativa al código que la identifica (que es lo comprehendido, lo recogido o abrazado como tal realidad) y a la inteligibilidad que el propio código proyecta sobre lo identificado. El cierre hermético y circularmente recursivo entre código —o sistema lengua-lenguaje-, realidad y comprensión es lo que subjetivamente se manifiesta como certeza, esto es, como presunción de haber logrado una intelección objetiva y progresivamente completa de la realidad, a medida que la investigación avance (pero siempre desde el interior de esa espiral centrífuga). La gnoseología del naturalismo 
José Domingo Vilaplana

es, según cabe sospechar, realista, redundante y recursiva. El discurso científico natural es, pues, un discurso autosostenido (en su propia dinámica centrífuga).

\subsection{Descripción, explicación, justificación}

Si entender y comprender polarizan desde el sujeto tanto el señalamiento selectivo de la realidad como su presunta objetivación en forma de conocimiento cierto, de certeza, estos tres conceptos pretenden ser de la realidad, de ella se predican como distensiones objetivadas de su comprensión cierta, por tanto igualmente manifiestas en el relato científico. En el relato, pues, encontramos descrita, explicada y justificada la realidad en su modo de ser; encontramos la realidad explicitada. Con frecuencia la delimitación y el alcance de lo que estos términos, tanto en su forma verbal como sustantiva, expresan no forma parte de los problemas a los que se enfrenta el autor del texto científico, de ahí que la alusión a ellos por parte del autor del relato científico sea laxa y llena de sobrentendidos, a pesar de que sólo gracias a ellos hay expresión de lo comprendido, hay conocimiento. Sin embargo, lo que el autor pretende, y presume haber realizado en su relato, es precisamente eso: dar cuenta descriptiva de sus observaciones, exponer sus hipótesis de partida, describir y explicar los experimentos que realiza, exponer sus resultados, e interpretarlos en lo que propone como explicación comprensiva e incluso justificativa. ¿Qué es lo que, no obstante, opera como garantía de que de lo que se está tratando: el objeto de la investigación y sus resultados, lo son de una realidad objetiva? A mi juicio, ya se ha dicho, tal garantía descansa en la comprensión misma, que es siempre comprensión $d e$, y siendo así pone lo comprendido como realidad de la que habla el sistema lengua-lenguaje que informa o ahorma su comprensión. Luego la realidad que objetiva la comprensión es en última instancia objetivada en el relato que de ella se hace; relato que abarca desde el entendimiento que la señala, hasta la comprensión que la objetiva en su definición, en su delimitación. Las descripciones, explicaciones y justificaciones son siempre y 
sólo lingüísticas, y son de la realidad por una exigencia refleja del entender y del comprender. La realidad es, pues, lo que relata el texto, pero en tanto relato, puesto que a relato es sometido y reducido inevitablemente lo que llamamos real. (¿Qué hay, entonces, de la realidad extratextual? Abordaré esta cuestión en el epígrafe siguiente, pero ya late problemáticamente en el análisis que realizamos.) Describir, explicar, justificar es construirla realidad comprensivamente. Desde esta perspectiva, todos los relatos que la ciencia natural produce, si pudieran ser ensamblados e integrados como las piezas de un mecano, conformarían la totalidad de la realidad comprendida. El solapamiento comprehensión (polo ónico)-comprensión (polo mental) genera la ilusión (la defectuosa visión) de que la comprensión (en sentido mental) lo es de algo concreto (en sentido extratextual) y de que ello (presunta realidad extratextual) es lo comprendido. La ilusión que se produce es la presunción de que al establecerse entre el ello y lo comprendido relatado una relación biunívoca (como necesariamente ha de ser, puesto que lo comprendido lo es puesto por la comprensión), el polo óntico es equiparado a lo comprendido. Se produce así la ilusión de que la comprensión relatada lo es de la realidad presuntamente subsumida en ella, o de algo que es real en sentido extratextual.

Esta ilusión es la ilusión realista, es la ilusión de la que se nutren el cientismo y el naturalismo. Una ilusión avalada por sus innegables logros y mantenida por sus ilimitadas expectativas. Logros y expectativas que requieren ser justivalorados a la luz de lo que este análisis gnoseológíco parece poner de manifiesto. Antes de abordar esta cuestión capital es preciso continuar con el análisis hasta hacer aflorar lo que pretendo hacer ver.

La descripción no es ni mera enumeración cuantitativa ni mera constatación; la descripción es ya comprensión y como tal se expresa a modo de explicación, aunque en ella se pueda recurrir a la enumeración o a la cuantificación y a la identificación de rasgos cualitativos. Hablamos, pues, de "explicación descriptiva", una primera instancia explicativo-comprensiva desde la que se instaura un orden de realidad que reclama seguir siendo investigado para ser comprendido a otros niveles, acaso genéticos o causales 
y funcionales. El resultado, o los resultados, de la investigación, son siempre concluyentes en un sentido o en otro, es decir: en sentido negativo (rechazable) o en sentido positivo (aceptable); en cualquier caso, ambas formas de resultados se incorporan al relato, en sus versiones implícita y explícita. Esta consideración es importante, porque tanto lo que se rechaza (por erróneo) como lo que se acepta (por verdadero) está marcado por la presunción de ser realidad comprendida, de otro modo no sería posible rechazar un resultado o una interpretación, como tampoco aceptarla. Por otro lado, el relato explícito de lo comprendido adopta la forma narrativa de la "explicación justificativa”, segunda instancia explicativo-comprensiva donde a mi juicio se manifiesta una nueva presunción que refuerza la impresión subjetiva de certeza, es decir, la impresión de objetividad y de completud: tal es la presunción de justificación, a la que ya nos habíamos aproximado, pero sobre la que volveré enseguida. Por su parte, "explicar" es "deshacer pliegues", por tanto "explicitar", exponer mostrando los plegamientos que previamente se hallaban cerrados sobre sí ocultando..., ocultando qué. ¿Qué ocultan los pliegues de la realidad? Reparemos en esta pregunta crucial, porque la propia idea de "explicación" parece comportar la de "ocultación", lo que a su vez genera al menos dos importantes implicaciones lógicas: una, lo oculto es siempre lo no comprendido; otra, mientras haya búsqueda comprensiva habrá algo oculto por comprender. Veamos a dónde nos conducen estas consideraciones sobre la comprensión y la explicación de lo oculto o lo plegado.

La realidad sólo es plegada para el sujeto, que es quien busca; sólo para él hay realidad oculta, no manifiesta; lo que equivale a decir que sólo para él la realidad es ignota. Desplegarla es hacer manifiesto lo oculto, lo no manifiesto: desextrañarla y traerla al mundo comprendido. Pero el despliegue de lo oculto sólo es posible como extensión de lo manifiesto (por eso "entender" lo es siempre desde lo comprendido); sólo desde lo manifiesto comprendido se accede progresivamente hacia y a lo oculto sospechado o 
imaginado. En rigor, nada hay oculto si no hay comprensión ${ }^{12}$. ¿Qué ocultan entonces los supuestos plegamientos de lo real? En cierto sentido, de no menor consideración, y al margen de la comprensión: nada, no ocultan nada, hasta que la comprensión que busco lo halla, es decir lo pone. No lo halla la búsqueda comprensiva, como realistamente se presume, sino que lo pone la comprensión que busco. Y lo halla, es decir experimenta la ilusión del hallazgo, cuando lo identifica y lo expresa, cuando lo nombra, y lo incorpora o lo integra al relato en términos descriptivos, genético-causales o funcionales, esto es, relacionales ${ }^{13}$. Hay hallazgo, pues, cuando se produce esa ilusión de solapamiento, esa ficticia fusión entre el nombre y lo nombrado ${ }^{14}$, en virtud de la cual lo comprehendido (a modo de polo óntico) se constituye como real, pero —no se olvide- sólo por haberse generado una comprensión, anclada en comprensiones previas, que ante todo consiste en la presunción de atribuir realidad y sentido a lo comprendido en el relato, pero que no es más que lo comprendido como relato. Es por esto que el relato científico tiende a constituirse, en un límite inalcanzable, porque alcanzarlo supondría el cese de la búsqueda, en una unidad de sentido comprendido y completo (tanto en términos comprehensivos como comprensivos).

Una explicación comprensiva como la que pretende expresar el relato científico, en tanto a través de sí presume establecer el polo óntico significado en ella (y así se consuma lo que hemos llamado la "ilusión realista", que involucra la ilusión naturalista), por su propia condición se erige en explicación no sólo justificativa, sino justificadora, y esto en un doble sentido. Primero, en el sentido ya señalado de comportar el "establecimiento" del

12 La comprensión pone la realidad porque previamente ha puesto lo oculto. Desocultar, o en terminología clásica: "descubrir", es, desde la tesis que defiendo, objetivar la realidad, no hallarla. La realidad sólo es realidad comprendida; por tanto, la búsqueda de realidad es tan inagotable como la búsqueda de comprensión; no se agota, pues, la comprensión en el límite de la realidad, sino la realidad en el límite de la comprensión. Contra la ilusión natural-realista.

13 De ahí la eficacia de la matemática, especialmente del álgebra, en la modelización comprensiva de lo oculto o lo plegado.

14 Ficticia porque no existe, es el nombre quien pone lo nombrado. 
polo óntico, es decir de fundar la presunta realidad que se desoculta, se identifica y se conoce; segundo, en el sentido de "justificar" su existencia. "Establecer", en sentido justificativo poner, o fundar, y "justificar" no son estrictamente la misma acción, ni en este contexto ni en otros, ni son equiparables como categorías gnoseológicas. Pero en este contexto sí se produce un sutil deslizamiento —otro más- de lo uno ("establecer": poner, o fundar) a lo otro ("justificar"), y viceversa. La "justificación”, por ese uso laxo de los términos sobre el que ya he llamado la atención, sutilmente pasa por asociarse y asimilarse a "explicación causal" 15 , que es lo que la gnoseología de la comprensión exige como condición para la comprensión total de un hecho o un proceso tenidos por reales. Así, dado que la comprensión funda lo comprendido en su mismo acto de comprender, de ahí que lo real comprendido presuma no serlo sólo en el relato explicativo, también en ese mismo relato, y bajo la misma presunción, queda justificada causalmente su existencia. Ese sutil deslizamiento hacia la justificación desde la comprensión causal (meramente justificativa) refuerza y reafirma la ilusión de certeza y completud que el relato inteligible comporta o connota desde su misma configuración en el sistema lengua-lenguaje. De este modo, el relato científico naturalista presume erigirse, a tenor de estas consideraciones, no sólo en el discurso descriptivo y explicativo de la realidad, sino en su misma justificación, esto es en la justificación de la existencia misma.

Insistiremos en mostrar el delicado mecanismo asimilador de la justificación por la explicación causal y las consecuencias que apareja.

15 Quiero decir que a eso, a "explicación causal”, se traduce lo que la auténtica "justificación” demanda; y nada más falaz que esa aviesa reducción de la "justificación” a "explicación causal": es tanto como pretender hacer accesible a la comprensión humana la "justificación" de su existencia ofreciendo de ella tan sólo "explicaciones causales" o "relacionales" de la realidad. A falta de auténtica "justificación" se pretende sustituir por lo que no llega ni a sucedáneo. Pero, ¿qué entiendo que sería auténticamente "justificar"? Lo veremos enseguida. 


\section{La ilusión naturalista y sus límites}

He tratado de hacer ver que la ilusión naturalista es el resultado de la integración de otras ilusionadas presunciones, a su vez inducidas por la desmedida presunción intelectual del hombre occidental, que hunde sus raíces en las tradiciones griega y latina. Igualmente, la ilusión naturalista y la presunción intelectual que la inspira son reforzadas y retroalimentadas por otra ficción, en este caso probatoria, la que llamo "prueba de uso" o "prueba de la obediencia debida". Intentaré hacer más visible esa ilusión naturalista, primero, y exponer la ilusa mecánica de la "prueba de uso" como ficción probatoria y reforzadora, después.

Con la expresión "ilusión naturalista" pretendo identificar lo que respecto de sí misma provoca la expectativa de comprensión ilimitada, fundamento del naturalismo científico. Es importante, en este momento especialmente, asumir como nota distintiva del naturalismo su pretensión de una comprensión ilimitada y completa de la realidad, lo que incluye la determinación misma de lo que sea realidad natural ${ }^{16,}$.y por extensión, de lo que sea real. E ilimitada en dos sentidos: sin término temporal y sin límite material. La ausencia de límite temporal alude a una búsqueda constante, interminable: es inimaginable el instante histórico en que la búsqueda cese porque el afán de comprensión de la realidad natural se haya humanamente colmado; por su lado, la ausencia de límite material alude doblemente a la ausencia de límites intelectuales y a la ausencia de límites en la inteligibilidad de lo real. De este modo, la presunción de ausencia de

16 Ya he señalado que el cientismo es inseparable del naturalismo, por tanto, éste asume plenamente la teoría del conocimiento que el cientismo promueve y desaprensivamente practica. Y lo hace así porque no necesita ser más precavido para lograr sus fines, que no son tanto el conocimiento de la realidad como su dominio, que es algo muy distinto. Señalo en este momento el sutil desplazamiento que históricamente se ha venido consumando desde la pretensión de conocimiento hacia la pretensión de dominio, y cómo ese desplazamiento se ha logrado presumiendo que dominar exige conocer, lo cual es una falaz y casi malévola imprecisión. Pero muy exitosa. Viento a favor. 
límites en los diversos sentidos indicados legitima la pretensión de objetividad, universalidad y completud del conocimiento que genera la ciencia natural y del naturalismo, así como su carácter reductivo y selectivo. Pero ¿qué cabe entender por "ausencia de límites en la inteligibilidad de lo real"?, ¿que la realidad es ilimitada o que es ilimitadamente accesible al intelecto humano?, ¿̇o ambas posibilidades? Una vez más la ilusión nace de caer en la trampa que las mismas palabras, con su indefinición, construyen. Veamos. Admitamos que la comprensión de la realidad que postula el naturalismo (conocer la realidad es comprenderla) presume que la inteligibilidad de lo real es plenamente accesible al intelecto humano, y admitamos también que el intelecto humano busca ilimitadamente esa comprensión. Sólo falta decidir si la realidad natural (literalmente: lo que está de acuerdo y deriva de la naturaleza) es o no ilimitada. No voy a tomar yo ahora esa decisión, ni voy a determinar en qué aspectos, por ejemplo temporal o material, sea la naturaleza limitada o no; quiero simplemente extraer algunas conclusiones lógicas en función de la premisa que asociemos a los dos supuestos de partida. 1. Si la naturaleza real está aquejada de alguna forma de límite, el que fuere, la búsqueda ilimitada de la comprensión de la naturaleza pondría de manifiesto una duda razonable acerca de lo que en el curso de esa búsqueda se identifica y se comprende como real, porque puede haber desbordado sus límites; esta duda puede no interrumpir la marcha triunfal de la ciencia ni la ejecución de los programas naturalistas, pero en el plano teórico representa una limitación a sus pretensiones y una deslegitimación, por principio, de tales programas, entre los que habría que señalar los relativos al mejoramiento humano y transhumanistas. 2. Si la naturaleza real es ilimitada, en la dimensión que fuere, nunca su comprensión llegaría a ser plena, aunque también fuera ilimitada, entre otros motivos porque no sería posible saber cuándo lo es o lo fue, y consiguientemente quedarían tocadas por la duda razonable todas las expectativas de la comprensión naturalista, que siempre sería limitada. Lógicamente, dos dominios colimitados, siendo cada uno ilimitado, son incomunicables, por 
ser heterogéneos. La comprensión, sí, tiende a ser plena respecto del presunto objeto real, pero siempre como una aspiración ilimitada de plenitud, lo que redunda en el carácter limitado (incluso en el sentido de impreciso) de la comprensión/conocimiento que logra. Cuanto menos, se trata de una inconsistencia de la tesis naturalista y cientista que neutraliza su pretensión de verdad y plenitud y limita drásticamente sus pretensiones programáticas. La presunción simultánea de una comprensión plena a la vez que ilimitada, sea la realidad limitada o no, es la contradicción que anida en la expresión "comprensión ilimitada", asociada a una búsqueda sin término. Pero esa contradicción, por más que sea flagrante, queda oculta por el ensalmo realista de las palabras y por el uso técnico que se hace del conocimiento.

La comprensión es, en efecto, ilimitada, puesto que, como he intentado hacer ver a lo largo de este análisis, pone la realidad que comprende, y lo podrá estar haciendo ilimitadamente. Por eso la realidad, desde el punto de vista de la comprensión, nunca se agota, es decir: ninguna comprensión la agota. Es ilimitada, pues, pero no porque no haya límites ni a la intelección de lo real ni a su inteligibilidad; al contrario: si ambas -intelección e inteligibilidad real- no tienen límites, entre ambas ha de existir un hiato insalvable. Como en efecto ocurre. ¿Qué salva, no obstante, ese hiato?, ¿qué fusiona intelección e inteligibilidad? Como digo, el hecho de que la misma comprensión pone lo real, lo explica y lo justifica, esto es lo que pretendidamente salva el hiato entre intelección (comprensión) e inteligibilidad real. La tendencia a conquistar una comprensión plena es así pretensión, y la comprensión conquistada, presunción de conocimiento. Hago notar, sin embargo, que bajo este supuesto, en un sentido, la comprensión conquistada, y explicitada en el discurso explicativo-comprensivo, siempre es completa (por tal se tiene), puesto que es el resultado de hallar lo que busca, esto es: de ponerlo en el relato, vicario de la realidad signada. Lo que sucede es que la búsqueda es ilimitada, por eso la comprensión, en este sentido principal, nunca es completa, porque nunca terminará de poner toda la realidad. Es siempre completa en tanto pone lo comprendido como 
comprendido; nunca es completa en tanto nunca deja de poner comprensión. La ilusión naturalista se alimenta de esta paradoja urdida por el mágico efecto de las palabras.

Una de esas palabras de mágica efectividad, en este contexto, y posiblemente en todos, es "justificación". A mi juicio, la "presunción de justificación" constituye la pieza maestra de la ilusión naturalista. He considerado más arriba a la "explicación justificativa" como la segunda instancia explicativa, aquella en la que se pretende haber tocado la raíz, o alguna de sus raíces, de lo real comprendido. Por eso suele tomarse "explicación", sin más, por “justificación”, de ahí que la pretensión de comprensión plena deslice y sustituya el contenido semántico de "explicación": despliegue, hacia y por el de "justificación”. Así, la explicación comporta (léase, cree comportar) la justificación, porque es justificación lo que en última instancia busca la comprensión. En rigor, el límite de la búsqueda comprensiva sería el hallazgo de la justificación absoluta, ésa sería la comprensión plena. Pero, ¿̇qué es justificar? Y ¿qué es justificación? La mera consulta al diccionario pone de manifiesto la exitosa popularización del uso de estos vocablos (cifra del éxito social del naturalismo, en cualquiera de sus versiones), de modo que su significado, inevitablemente difuso, es el resultado de fundir conceptos (también altamente popularizados: razón, causa, motivo, prueba...) en la difusa actividad intelectual que los concibe (demostrar, probar, razonar..., también muy popularizada) ${ }^{17}$ en favor de una comprensión realmente (o sea, supuestamente) lograda a base de argumentos explicativos y probatorios. Esto hace que, sin más, cualquier explicación debidamente urdida sea tomada por justificación, insisto: reforzando así el valor y la hondura de la comprensión, es decir, reforzando la certeza. Presumir la dimensión "justificadora” (más allá, pues, de la dimensión "justificativa”) de la explicación

17 Por esto, todo el mundo entiende la expresión "científicamente probado", pero no la comprende. Es decir, entiende las palabras, pero no comprende en profundidad lo que dicen. Sencillamente lo asocia a otros sobrentendidos. A esto es a lo que se llama "acercar la ciencia a la sociedad", a generar sobrentendidos accesibles que redunden en la propia sacralización de la ciencia y en el estímulo de su demanda social. Viento a favor. 
naturalista es lo que presenta al naturalismo, y con ello a la ciencia natural, como formas absolutas de conocimiento, porque está en sus presumidas facultades justificar el conocimiento de lo real. Pero justificar el conocimiento de lo real no es justificar la realidad, sino acaso aportar elementos justificativos, o sea relacionales. Lo que sucede es que esos elementos justificativos justifican la realidad en tanto es puesta por la comprensión, por tanto se "justifica" lo que se pone. Una vez más se produce un deslizamiento semántico, en este caso, de lo "justificativo" a la "justificación”. ¿Qué serían, vuelvo a preguntar, justificar y justificación? Algo, en rigor, imposible para la explicación/comprensión: poner la existencia misma. Y esto no lo hace ni la explicación ni la justificación que ésta supuestamente comporta en términos de identificar génesis causales, es decir relacionales. Y no la pone porque es inaprehensible comprensivamente, porque no procede de la extensión o amplificación del mundo comprendido, sino que es previa lógicamente a él. La existencia, pues, queda fuera, siempre, de la comprensión y, consiguientemente, de la explicación. Lo que no se pone, porque es condición del mismo poner, esto es, la misma existencia, no se justifica, por tanto ni se explica ni se comprende.

Llegados a este punto del análisis, dos son al menos los límites o limitaciones que manifiesta la comprensión naturalista: 1. Está limitada por el hecho de que la comprensión, al ser siempre de, pone en el mismo acto comprensivo la realidad en tanto comprendida ${ }^{18} ; 2$. Está limitada en su capacidad comprensiva, en tanto le es imposible poner la existencia sobre la que edifica lo comprendido, la existencia misma de la realidad o mundo extratextual. Consecuencia de la primera limitación es que todo lo que no logre ser establecido por una comprensión condicionada a las restricciones del método científico, sencillamente no existe, o existe sólo en los términos

18 La comprensión, al ser siempre de, procede siempre de un mundo comprendido: la comprensión amplía o extiende el mundo comprendido ilimitadamente; pero la comprensión opera desde dentro del mundo, no desde lo que "le hace justicia", que está irremediablemente fuera, es externo a él. El mundo no es autojustificado, como el automóvil no es autónomo, por más que lo parezcan. 
que esa metodología permita establecer y traducir, es decir incorporar al relato científico naturalista. Consecuencia de la segunda limitación, que considero de una trascendencia capital, es la imposibilidad de dar justificación, ni próxima ni última, de lo existente: esa justificación no está presente en la realidad comprendida, lo que, consecuentemente, reduce significativamente el alcance justificador de la explicación, que nunca podrá ser pleno. La comprensión, pues, es mucho menor y mucho más estrecha de lo presumido en el relato científico, por más que en él brille esa ilusión de completud y de inatacable objetividad: si se sigue buscando, se sigue encontrando, ilimitadamente, pero lo que nunca se encuentra es lo que queda fuera, lo que no se comprende, lo incomprensible: la justificación. Tras la frontera de la compresión explicativa de lo real está la justificación de la real existencia misma. Es lo que pertenece al plano del misterio.

\subsection{Mundo extratextual y "Prueba de uso"}

Ya señalé más arriba que los pliegues de lo real sólo ocultan lo que busco, puesto que si no hay búsqueda intelectual comprensiva no hay realidad oculta. Esto plantea, de un lado, la pregunta, que ya gravita sobre lo expuesto hasta ahora: ¿qué hay, en ausencia de búsqueda intelectual comprensiva?; pero de otro, reedita el problema de la comprensión justificadora, que se resiste a reducirse a comprensión justificativa o justificada: ¿acaso no es una prueba justificadora la facultad de uso técnico del conocimiento científico, es decir, de la explicación comprensiva?

Soy consciente de las connotaciones que a cualquier lector le puede sugerir la expresión "realidad extratextual”. En el contexto de este análisis he establecido una correlación entre "realidad natural" y "realidad narrada o relatada en el discurso científico", puesto que éste pretende ser siempre de la realidad natural. La comprensión de la que el discurso científico da muestra es comprensión de la realidad que pone la comprensión misma. Esta es una de las tesis centrales que postulo y que he intentado mostrar. "Realidad 
extratextual" involucra tanto a la realidad no comprendida, por tanto no expresada en el relato científico: realidad no explicada, como a la justificación de la realidad, inaprehensible desde cualquier forma de comprensión, puesto que es lo único que la comprensión no puede poner, pero inherente a todo lo comprendido. Entre la realidad no explicada (desconocida) y la injustificabilidad de la realidad no hay más distancia que entre ésta y la realidad explicada. Su existencia es anterior lógicamente, injustificable e incomprensible. La realidad extratextual no es exactamente una versión actualizada de la "cosa en sî" kantiana, porque la "cosa en sí” no es equiparada por Kant ni a la nuda existencia ni a la realidad no comprendida, sino a la realidad incognoscible, o sea a la realidad, en términos kantianos, auténticamente existente, pero inaccesible a la comprensión científica. Creo que hay un matiz claramente diferenciador, favorable a mi tesis, de resonancias más berkeleyeanas que kantianas (puestos a rastrear ecos y resonancias). Yo defiendo que no hay más realidad que la comprendida, pero en tanto que comprendida; y también defiendo que tanto lo comprendido como lo aún por comprender están sustentados en una existencia injustificable para la comprensión, que puede ponerlo todo menos la existencia. ¿Qué hay, en ausencia de búsqueda intelectual comprensiva? Nada, salvo el mundo comprendido, el mundo familiar encontrado, no buscado, carente de pliegues, aproblemático en sentido filosófico ${ }^{19}$. ¿Qué hay, ajeno a cualquier forma de comprensión posible, mundana o científica, es decir: plegada o desplegada? La existencia. Sólo sobre ella edificamos la realidad de la que no podemos escapar, tan sólo ampliar, ilimitadamente.

La técnica es ampliación de la realidad comprendida, y en su versión actual es la externalización práctica (traducción amplificada) de la realidad

19 Es el aproblematismo en el que vive la casi totalidad de la comunidad humana. Los problemas de la vida cotidiana en las comunidades humanas no son de índole filosófica, al contrario, son solubles con las herramientas y los intrumentos disponibles, entre los que se hallan la lógica, en su versión del sentido común, el caudal de la tradición y toda la asistencia tecnocientífica disponible en cada momento histórico. Circunscribir la vida a esos parámetros es estrictamente vivir en el horizonte de lo cotidiano, del mundo comprendido. Los problemas no pasan de ser problemas domésticos. Hasta la muerte está comenzando a serlo. 
comprendida en el discurso científico, realidad cuya comprensión se refuerza en la medida en que es dominada. ¿No es entonces su funcionamiento a nivel de uso la prueba fehaciente de que la comprensión que la hace posible lo es de la realidad? Desde las coordenadas de la asociación comprensión-dominio-conocimiento, sin duda lo es, porque lo que verdaderamente funciona es la realidad que se ha puesto, no otra preexistente, como presume el realismo cientista; es decir, la realidad es puesta en su comprensión, por tanto si sometemos lo comprendido a las pruebas que lo hicieron posible, éstas refuerzan la comprensión, así como la comprensión se apoya en las pruebas: la resultante de esta mutua apoyatura es la certidumbre que inspira el dominio probatorio. Experimentar es condicionar un resultado desde el propio diseño del experimento, es una forma de externalización técnica, como toda tecnología es externalización de la comprensión; pero será ese resultado, el que arroje la externalización experimental, el que será interpretado, luego resultado e interpretación se encuentran coimplicados desde su origen. Interpretación y experimento, como interpretación y observación, se obedecen mutuamente, no puede ser de otro modo. La prueba es siempre de "obediencia debida", porque la prueba no puede emerger sino de la comprensión; es más, la prueba es comprensión externalizada; por eso, pese a Popper, siempre se buscan casos confirmadores. Desde esta perspectiva, la refutación o falsación popperianas no son sino formas más sofisticadas de conquistar la obediencia (por la vía de la resistencia), es decir la confirmación, que es a lo que llamó el sabio austriaco "conocimiento objetivo" ${ }^{20}$. Del mismo modo que las demostraciones lógicas y matemáticas son autorrecurrentes respecto a sus principios axiomáticos, las pruebas empíricas lo son respecto a las condiciones léxico-

20 Aparte de que Popper lo que trataba era de evitar la dogmatización de las teorías científicas, que suponen una limitación a su progreso, a la ilimitada apertura que —a su juicioha de caracterizar a la investigación científica. Creo, no obstante, que tratar de evitar la dogmatización de las teorías científicas, a la vez que postular una investigación sin límites, no le impidió contribuir a la consolidación del dogma de la ciencia. 
lingüísticas de la comprensión, que son las que establecen el dominio práctico y probatorio de la realidad. Lo que la prueba establece es, pues, tan sólo un comportamiento susceptible de ser previsto desde lo comprendido, satisfaciendo así el afán de dominio, no tanto el de conocimiento. Por eso todo experimento, no sólo parte de una comprensión previa, sino que en ella anida ya una previsión sospechada; es decir, el experimento busca algo que ya está de alguna manera preconcebido en el mismo. La historia de los hallazgos probados, por ejemplo, siguiendo la exposición que de ellos hace Kandel respecto de la Neurociencia, en su artículo del mismo nombre, como en cualquier otra disciplina entre las consideradas científicas, es la historia del sucesivo encadenamiento de sospechas y búsquedas integradas en comprensiones cada vez más amplificadas e integradoras, sometidas constantemente a unos procesos de traducción de unas a otras, de intertraducción, que van configurando el relato de lo conocido, es decir el relato de lo concebido como realidad: un relato que va configurando, pues, el plano de la realidad. Un relato que no tiene fin, como no tiene fin su traducción: la externalización tecnológica. Por eso, en rigor, no hay pruebas concluyentes, salvo transitoriamente, como no hay una tecnología definitiva. Esas pruebas sólo transitoriamente concluyentes constituyen el dominio de lo "justificativo", que es integrado en el relato comprensivo de la realidad, bien explícita, bien implícitamente, y adopta la forma de relación causal. Ese carácter relacional que adopta lo "justificativo" al nutrir por todas las vías explicativas, tanto históricas como empíricas y experimentales, el esquematismo causal que demanda la comprensión de lo real, no sólo configura el plano de la realidad, como antes señalaba, sino que al ofrecer de ella una imagen orgánica, de totalidad armonizada en términos de un orden causal, refuerza la presunción de unidad y completud no ya de la comprensión (que sí tiende a ello), también de lo comprendido, rehabilitando la ilusión realista, es decir la presunción que identifica de con $l o$, o la presunción de que hay lo sin de, y que el de lo es del lo. Así, la justificación en términos causales, que en principio sólo puede tener un alcance local (a nivel justificativo de procesos asícomprendidos), se extrapola, además de a 
José Domingo Vilaplana

la totalidad orgánica de la realidad comprendida (es decir, a la totalidad de lo real que pone y pondrá ilimitadamente la comprensión), a dos ámbitos más que así quedan fundidos o fusionados en términos causales, induciendo la comisión del error base que a su vez inspira, entre otros, el error naturalista. Me refiero, de un lado, al ámbito ilusorio de la realidad considerada en clave realista (que es la que adoptan el naturalismo y el cientismo), y de otro al ámbito necesario de la existencia. En efecto, se produce un deslizamiento metonímico del de que establece o pone la comprensión al lo que supone (sub-pone) el realismo, de modo que la comprensión "justificativa" muta en realista "justificación", o lo que es lo mismo: la causa justificativa muta en causa justificadora. Ello conduce en términos realistas a la comisión de lo que, como ya señalé, constituye a mi juicio el exceso teórico de resultados más perversos: adoptar la causa justificadora, que no pasa de ser justificativa, como causa fundadora de la existencia. Lo que comienza siendo un modo de comprensión de la realidad, habilitando causas justificativas de los procesos de la realidad que la comprensión pone, absorbido por la presunción realista muta en la fuente justificadora de la existencia. De ahí que desaprensivamente en los relatos científicos no haya diferencias entre explicación y justificación: supuestamente la primera trae incorporada la segunda, así lo que pretendidamente se explica es "la razón de ser de la realidad explicada", razón que se despliega en la génesis causal que justifica la propia existencia real. A partir de ahí la ciencia natural, ya abierta y declaradamente cientista, y el naturalismo que la adopta, imponen una nueva renuncia, o lo que viene a ser lo mismo: imponen una nueva prohibición (por declarar inútil e infructuoso el esfuerzo), la de preguntarse (y consiguientemente buscar) el principio justificador de la existencia, que es lo único que queda fuera del alcance de la comprensión en términos causales o justificativos, es decir lo único que queda fuera para/de la realidad de la ciencia. Pero sin existencia no hay nada. La ciencia lo sabe, pero resuelve, o pretende resolver, el problema del origen en términos realistas y empíricos, o sea en términos de dominio, y lo que le sale es un confuso origen de 
la materia (vicario del creacionismo) y, en su estela, una existencia autogenerada, por tanto comprendida en sus propias causas incausadas, esto es, divinizada (por más que le pese), y llena de derivadas evolucionistas que insisten en confundir cambio y transformación con justificación real, pero esto la ciencia no lo sabe, o no parece interesarle saber.

Asunto que en estos prolegómenos queda sin desarrollar, pero demanda una seria incursión teórica, es la exploración de otras vías comprensivas del origen de la existencia. Sólo sé que esa comprensión no podrá ser de carácter científico, tal como yo lo entiendo, y aún menos en términos ingenuamente realistas, tan burdamente desaprensivos, pero tan exitosos (nunca el "Erbarme dich" de la Pasión Según San Mateo de Bach será canción del verano). Y ni siquiera sé si será posible lograr tal comprensión, ni, si acaso, fuera comunicable mediante el sistema lengua-lenguaje, a pesar de su ilimitada sofisticación.

\section{Grandeza y miseria del naturalismo. Conclusiones parciales}

Soy muy consciente de los mil rostros que puede presentar el naturalismo, tantos probablemente como naturalistas, cada uno de ellos con rasgos propios que los diferencian hasta el punto de hacer difícil adscribirlos en una categoría común, y acaso ni falta que haga. Sobre algunas formas de naturalismo y lo que defienden los autores que las patrocinan trataremos en otro lugar. No obstante, la versión del naturalismo que he adoptado como referencia en este análisis es la que involucra las siguientes caracterizaciones: fisicalista-mecanicista, materialista, biologicista, evolucionista y, por supuesto, cientista. Por tanto, entiendo como rasgo general de cualquier forma de naturalismo, el cientismo, esto es la consideración de la superioridad del conocimiento científico respecto a cualquier otra forma de conocimiento, y muy especialmente respecto del conocimiento filosófico, o lo que pretende serlo, que también es extraordinariamente dispar entre los mismos filósofos. De entrada, esto ya supone que los naturalistas han de 
José Domingo Vilaplana

sentirse incómodos bajo la consideración de filósofos: esto sucede en diverso grado de rechazo, llegando algunos a la pretensión de practicar una actividad mimética a la ciencia; de igual modo, el naturalismo que profesan en verdad huiría de, o tendería a evitar, ser considerado una corriente filosófica, o una corriente más en la historia de la filosofía, para, al amparo de la ciencia, erigirse algo así como en una forma sólida y avanzada de pensamiento científico, es decir de pensamiento instruido desde la solidez y el prestigio de la ciencia, incluidos sus métodos; una forma de pensamiento, pues, libre o liberado de la infructuosa manía especulativa, que si no es esencialista es nominalista, que si no dualista, monista, pero de ahí no sale (entiéndase la ironía). Esto hace plantearme, en otro orden de problemas que no es momento de abordar, la cuestión de si cabe ser considerado filósofo a quien reniega de serlo, y filosófica a una corriente que, igualmente, rechaza las connotaciones negativas que desde cierta consideración del quehacer filosófico y de la filosofía le fueran atribuibles precisamente por filosófica. En cualquier caso, pienso que el naturalismo es inseparable de la ciencia, pues en lo que tenga de filosofía, o de corriente de pensamiento, ésta nace de una valoración y una proyección del hacer científico, a modo de implicaciones doctrinales de dicho quehacer, lo que, de facto, convierte, no ya al naturalismo como doctrina, sino al programa naturalista, en una extensión de la propia ciencia. Por este motivo, un análisis de las tesis naturalistas no es que fuera incompleto, sino manifiestamente infundado si no involucra un análisis del conocimiento científico que el naturalismo asume y pondera sobre cualquier otro no-científico, y sobre el que en definitiva apoya la legitimidad de su programa, una legitimidad pretendidamente científica. Este posicionamiento teórico es, por lo demás, ciertamente arriesgado, dado que la crítica a uno arrastra al otro y viceversa; es decir, se abaten, o se dejan tocadas, si se acierta en el análisis, dos piezas con el mismo disparo: la crítica al conocimiento científico supondría un duro golpe al naturalismo, y al contrario: la crítica al naturalismo interpelaría a la ciencia no ya respecto de sus fines, que sí, sino respecto de algo más radical: 
la garantía de su presunción (que estará cifrada, antes que en la verdad objetiva de su conocimiento, en la eficacia con que satisface la humana necesidad de dominio). Esto pone de manifiesto el vínculo tan estrecho entre ciencia y naturalismo, que a mi juicio en la actualidad se coimplican. A su vez, esta coimplicación, si consideramos que pese a los naturalistas el naturalismo no logra dejar de ser una filosofía, conduce a un renovado, y acaso inesperado, acercamiento entre ciencia y filosofía, puesto que en cierto modo la primera no deja de serlo, es decir no deja de ser filosofía, o una extensión de la búsqueda filosófica, y la segunda resulta ser algo más que a lo que la ciencia pretendía haberla relegado. Pero al margen de estos posicionamientos teóricos y sus consecuencias, más o menos asumidas, un análisis crítico del naturalismo ha de tener en el punto de mira al mismo conocimiento científico, bien para discutir y analizar lo que le otorga cientificidad: sería una crítica de carácter epistemológico, bien para discutir y analizar las bases y el fundamento de su objetividad: sería una crítica de carácter más propio de la filosofía del conocimiento, con derivaciones tanto gnoseológicas como lógico-lingüísticas o analíticas. He adscrito el ejercicio crítico realizado en estos prolegómenos al ámbito de lo que llamo, cruzando territorios vallados, "gnoseología del naturalismo", en un intento de vincular lo gnoseológico a lo doctrinal, pero también lo gnoseológico a lo lingüístico, precisamente desde la consideración de que no hay ni ciencia ni conocimiento ni doctrina sin lengua y sin lenguaje; es más, el encadenamiento cohesivo del discurso científico al discurso doctrinal se realiza también mediante un ensamblaje terminológico en que las imprecisiones léxicas y las contaminaciones interdisciplinares son hábilmente utilizadas en favor de lograr el brillo efectista de la doctrina naturalista, brillo que recibe, como la luna del sol, del brillante prestigio de la ciencia misma. Pero es que, vengo defendiendo en este trabajo, también el discurso científico es un discurso efectista, y su efectismo emerge de su lenguaje y se refuerza en la ingenua certidumbre que aporta la prueba y su proyección (los dos momentos de la externalización de la comprensión) en forma de dominio técnico. A sondear este juego efectista del discurso científico, es decir: a 
tratar de identificar algunos de los mecanismos que provocan el ensalmo psicológico por el que se otorga realidad objetiva a lo que pretendidamente ha sido comprendido, he dedicado este ensayo, si se quiere, seminal, es decir abierto a futuras fases de maduración. Así, hablar de ensalmo psicológico, ensamblaje terminológico, bases o fundamentos gnoselógicos, o simplemente discurso, narración o relato científicos, no es ya poner de manifiesto, sino dar por supuesto el hecho innegable de los límites, en este caso y de manera muy destacada, los límites del naturalismo como doctrina, pero aún antes: los propios límites del conocimiento científico, en tanto el naturalismo constituye su extensión doctrinal. Límites y limitaciones persistentes a pesar de los intentos de superación de las polisemias, imprecisiones y deslizamientos léxicos mediante todo tipo de estrategias, como la formalización lógica y terminológica, o la modelización y matematización, de que se sirve la investigación para construir su discurso. Estrategias inútiles, a mi modo de ver, porque el discurso científico se construye de espaldas a sus límites, por tanto ni los conoce ni puede superarlos. En efecto, lo que constituye la comprensión científica de lo real es un compendio de sucesivas traducciones de unos sistemas lingüísticos a otros y entre sí que arrastran una historia de hibridación léxica de tal consistencia y urdida desde una actitud tan desaprensivamente realista que ha producido como resultado lo que llamo "el plano de la realidad", una entidad autosostenida en los sistemas lenguaje-lengua que expresan explicativamente su comprensión, mas nunca esa comprensión puede serlo de sus propios límites: comprenderlos ya sería superarlos.

Dos son los motivos de que, a pesar de las múltiples objeciones a la pretensión de objetividad realista del conocimiento producidas en la historia de la filosofía, la ciencia continúe su marcha jalonada de triunfos, es decir de influyente prestigio. Uno, el efecto ensálmico o hipnótico que provoca en el sujeto la prueba experimental, empírica; otro, y muy destacable por la perversión que oculta: la reorientación ilustrada de la ciencia, plenamente consumada en la actualidad, desde la búsqueda clásica de conocimiento hacia la búsqueda de dominio. Se trata de la sustitución del conocimiento por 
el dominio. De hecho, se hace creer que el dominio de la realidad procede de su conocimiento, e incluso que éste lo legitima, y no es así: puedo dominar la realidad, es decir le puedo imponer mi voluntad, sin conocerla, es lo que cotidianamente sucede, y es lo que los seres humanos parecen necesitar, dominar, antes que conocer. (Por eso el conocer ha terminado reorientándose hacia el dominar; el conocimiento que buscaban los griegos se salía literalmente de lo comprensible, y amenazaba con una regresión al mito y a la religión, por eso con el tiempo ha claudicado en favor del dominio, una forma vicaria, y menor, de divinización: un dios menor, pero que aporta seguridad y rentabilidad. Lograr el conocimiento que buscaban los griegos suponía, literalmente, equipararse a los dioses mayores. En nuestra época, ese dios menor del dominio es pretendidamente el único, por eso ha crecido, se ha hecho mayor, y a él confiamos toda nuestra seguridad y rentabilidad, es decir nuestro presente y nuestro futuro.) Claro, con frecuencia, por no decir constantemente, y a diversas escalas, los seres humanos se llevan sorpresas, por creer que ahí donde decían dominio había conocimiento, y no lo había, había sólo una mecánica previsible que faculta para una tecnopráctica dominadora o dominante, que es lo que vicariamente se ha adoptado como conocimiento en sentido científico. Insisto, desde la Ilustración se viene renunciando a conocer, quizá por imposible, en favor del dominar, en favor de encontrar pautas mecánicas (léase, previsibles) apoyadas en una comprensión buscada y encontrada, en una espiral literalmente sin fin, pero sólo calificable de conocimiento real (en sentido realista) en un acto que tiene tanto de acrítico como de soberbio. ¿Queremos conocer el coronavirus o queremos dominarlo, es decir integrarlo en nuestro mundo comprendido y manejarlo, hacerlo presente y previsible, y así neutralizarlo, si lo deseamos? Sin duda, esto último, que no es estrictamente conocerlo, aunque lo parezca; si de verdad tuviéramos que conocerlo para protegernos de él posiblemente terminaríamos siendo sus víctimas. Y esto que desde una consideración filosófica abierta y desprejuiciada es casi un apriorismo: el de que toda forma doctrinal y de conocimiento es limitada (porque no puede ser en ningún sentido absoluta ni plena), o incluso simulada (lo que 
no quiere decir inútil o inservible, como tampoco en todo caso perversa ni rechazable de raíz), aplicado al conocimiento científico disuena como si se profiriera un sacrilegio, si no fuera porque desde las coordenadas comprensivas de la ciencia los sacrilegios no existen o responden a concepciones equívocas o directamente equivocadas de la realidad, mera quincalla teológica. ¿Quién se atreve a cuestionar, y aún menos con humildad y lleno de dudas, la presunción científico-naturalista? ¿Quién, desde la cueva de este confinamiento, cuestiona que dominar y neutralizar el virus sea conocerlo realmente?

La expresión "Grandeza y miseria del naturalismo" fue sugerida por el profesor Juan Arana precisamente como un modo de señalar, de un lado, la limitación implícita del naturalismo como doctrina, a lo que aquí añado la propia limitación del conocimiento científico, que es desde donde parecen afianzarse el fisicalismo, el materialismo y el biologicismo naturalistas, pero también, de otro lado, la espectacularidad del propio progreso científico, a mi entender cifrada en su capacidad de dominio, y lo que haya podido contribuir y siga contribuyendo al bienestar humano. No sé si esto concuerda con lo que el profesor Arana pretendía sugerir del naturalismo con esa doble y en cierto modo paradójica calificación de grande a la vez que mísero, pero es importante, al menos para fijar mi posición, señalar que bajo la consideración de "grandeza" entiendo que se esconde una pretensión excesiva y carente del debido fundamento, lo que augura su propia miseria: la pretensión de discernir reductivamente lo real de lo no real bajo la presunción de estar en condiciones de conquistar un conocimiento auténticamente objetivo y universalizable acerca de lo que realmente lo sea, definición que se realiza desde los mismos presupuestos científicos. A esta pretensión legitimada por un no menor exceso presuntuoso le sigue, en nombre de la ciencia, es decir avalado por ella, todo un programa de rediseño social y vital, un programa político-económico, de inspiración trans- o post- humanista, que es la singularidad a la que conduce, con el beneplácito del público, cada vez más atormentado a la vez que condicionado por sus frustraciones, entre las que ya destacan la enfermedad, la senectud y la muerte, el ilimitado por 
inatacable progreso científico. La miseria del naturalismo yo la entiendo, pues, en dos órdenes: por lo que presume y por lo que pretende, estando lo segundo amparado en lo primero. Presume una alianza con la ciencia, con el consiguiente deslizamiento del dominio técnico (patrimonializado por la ciencia) al dominio político, igualmente ilimitado en extensión y en intensión: el dominio de la realidad natural se extiende inevitablemente al dominio de la realidad humana, puesto que ésta es, cómo no, un producto -otro más- evolutivo de la naturaleza. La vocación del naturalismo es, ineludiblemente, de naturaleza ideológica, he ahí su miseria; su pretensión, por tanto, es ostentar una responsabilidad política, en cualquiera de sus flancos, a través de la promoción sin ambages de lo que hay que identificar como una "ideología científica", muy vinculada al cientificismo o cientismo, en virtud de la cual se legitimen cuantos proyectos de ingeniería humana y social entiendan sus ideólogos que materializan el progreso que demanda la humanidad, palabra que pronto aludirá a una forma primitiva de comunidad. (A la zaga de esta ideología científica se encuentran los saberes aspirantes a ser considerados científicos, como la economía, la sociología o incluso la pedagogía, que han olido la facultad dominadora que la condición de ciencias les otorga, dominio para cuyo ejercicio esa misma condición las legitima. La sombra del naturalismo, no se olvide, es muy alargada.)

Nuestro análisis, puesto que ya es también del lector, para que disponga de él a su libre antojo, se ha quedado en un estadio casi preliminar de la crítica al naturalismo o a los naturalismos, y a sus consecuencias programáticas. Se ha quedado, como antes apuntaba, en el intento de mostrar, de un lado, los resortes gnoseológicos del llamado conocimiento científico, sus inconsistencias y sus limitaciones, que no son ajenas al sistema lengualenguaje, desde el que se posibilita la comprensión y se elabora su explicación, ni a los subsistemas que se construyan ad hoc; de otro lado, nuestro análisis se ha quedado en un preliminar esfuerzo por mostrar los deslizamientos léxicos y las ilusiones que estos corrimientos y metonimias provocan, haciendo ver (espero) cómo estas ilusiones operan siempre a favor de corriente de las presunciones cientificistas y las pretensiones 
naturalistas, conformando un conglomerado terminológico que si no se estudia con lupa impide realizar cualquier deslinde señalador, crítico, de sus límites e inconsistencias. La alocada precipitación del progreso científico, imparable y arrollador, impide o dificulta cualquier intento de fijación de coordenadas y reconocimiento cabal de lo que se dice, se hace y hacia dónde nos conduce.

Un comentado análisis del mencionado artículo de E. R. Kandel y colaboradores, "Neurociencia", del año 2000, pienso que podría reforzar el intento metacomprensivo realizado en este trabajo, al señalar e identificar explícitamente, a través de ejemplos, lo que constituye el juego manifiesto de cacofonías léxicas, aliteraciones y recursiones que urden la trama del discurso científico. Que hubiera excedido en demasía los márgenes de este ensayo no desdice de su oportunidad ni es obstáculo para ser abordado en el futuro. La comprensión de la realidad que expresa el discurso científico es producto - ya se ha dicho- de una doble recidiva, que sosteniendo el discurso sustenta el plano de la realidad que presuntamente signa; tal recidiva, como he intentado mostrar, cabe ser formulada en estos términos: la comprensión se adquiere no sólo por el lenguaje, sino desde el lenguaje. Si examinamos con atención esta presunción significativa, lo que supone hacernos refractarios o resistentes al efecto hipnótico del discurso científico y de la magia probatoria de la prueba de dominio (sacralizada en forma de tecnología), se aprecia la peligrosidad que encierra enganchar a dicha presunción la pretensión naturalista, a la que no le es ajena, sino que está implícita en su propósito: promover la transformación social y la transformación humana por la vía de una ingeniería lingüística amparada en las formas que adopta el discurso científico. Quizá asistimos, sin habernos dado plena cuenta de ello, a la institucionalización de una perversa paráfrasis de la célebre tesis wittgensteiniana, que podría enunciarse así: los pliegues del lenguaje configuran los pliegues de lo real..., luego construyamos la realidad que queramos plegando a tal propósito el lenguaje. Creo que éste es el tema de nuestro tiempo.

José Domingo Vilaplana Guerrero jdomingov@hotmail.com 